\title{
Aberrant ER Stress Induced Neuronal-IFN $\beta$ Elicits White Matter Injury Due to Microglial Activation and T-Cell Infiltration after TBI
}

\author{
Tanusree Sen, ${ }^{1}$ @Pampa Saha, ${ }^{1}$ Rajaneesh Gupta, ${ }^{1}$ Lesley M. Foley, ${ }^{2}$ Tong Jiang, ${ }^{1}$ Olena S. Abakumova, ${ }^{1}$ \\ T. Kevin Hitchens, ${ }^{2}$ and ${ }^{\circ}$ Nilkantha Sen ${ }^{1}$ \\ ${ }^{1}$ Department of Neurological Surgery, University of Pittsburgh, Pittsburgh, Pennsylvania 15213, and ${ }^{2}$ Animal Imaging Center, School of Medicine, \\ University of Pittsburgh, Pittsburgh, Pennsylvania 15044
}

Persistent endoplasmic reticulum (ER) stress in neurons is associated with activation of inflammatory cells and subsequent neuroinflammation following traumatic brain injury (TBI); however, the underlying mechanism remains elusive. We found that induction of neuronal-ER stress, which was mostly characterized by an increase in phosphorylation of a protein kinase R-like ER kinase (PERK) leads to release of excess interferon (IFN) $\beta$ due to atypical activation of the neuronal-STING signaling pathway. IFN $\beta$ enforced activation and polarization of the primary microglial cells to inflammatory M1 phenotype with the secretion of a proinflammatory chemokine CXCL10 due to activation of STAT1 signaling. The secreted CXCL10, in turn, stimulated the T-cell infiltration by serving as the ligand and chemoattractant for CXCR3 ${ }^{+}$T-helper 1 (Th1) cells. The activation of microglial cells and infiltration of Th1 cells resulted in white matter injury, characterized by impaired myelin basic protein and neurofilament NF200, the reduced thickness of corpus callosum and external capsule, and decline of mature oligodendrocytes and oligodendrocyte precursor cells. Intranasal delivery of CXCL10 siRNA blocked Th1 infiltration but did not fully rescue microglial activation and white matter injury after TBI. However, impeding PERK-phosphorylation through the administration of GSK2656157 abrogated neuronal induction of IFN $\beta$, switched microglial polarization to M2 phenotype, prevented Th1 infiltration, and increased Th 2 and Treg levels. These events ultimately attenuated the white matter injury and improved anxiety and depressive-like behavior following TBI.

Key words: IFN; microglia; neuroinflammation; traumatic brain injury; white matter injury

Significance Statement

A recent clinical study showed that human brain trauma patients had enhanced expression of type-1 IFN; suggests that type-1 IFN signaling may potentially influence clinical outcome in TBI patients. However, it was not understood how TBI leads to an increase in IFN $\beta$ and whether induction of IFN $\beta$ has any influence on neuroinflammation, which is the primary reason for morbidity and mortality in TBI. Our study suggests that induction of PERK phosphorylation, a characteristic feature of ER stress is responsible for an increase in neuronal IFN $\beta$, which, in turn, activates microglial cells and subsequently manifests the infiltration of T cells to induce neuroinflammation and subsequently white matter injury. Blocking PERK phosphorylation using GSK2656157 (or PERK knockdown) the whole cascade of neuroinflammation was attenuated and improved cognitive function after TBI.

\section{Introduction}

Traumatic brain injury (TBI) is a major cause of morbidity and mortality and affects $>1.7$ million people throughout the United

\footnotetext{
Received March 29, 2019; revised Sept. 16, 2019; accepted 0ct. 17, 2019.

Author contributions: T.S. and N.S. designed research; T.S., P.S., R.G., L.M.F., T.J., O.S.A., T.K.H., and N.S. performed research; T.S. and P.S. contributed unpublished reagents/analytic tools; T.S., P.S., L.M.F., T.K.H., and N.S. analyzed data; T.S. and N.S. wrote the paper.

This work was partly supported by the National Institutes of Health (Grants R01NS094516 and R01EY025622 to N.S.), and the University of Pittsburgh and Copeland Foundation to T.S. and N.S.

The authors declare no competing financial interests.

Correspondence should be addressed to Tanusree Sen at tas215@pitt.edu or Nilkantha Sen at senn@pitt.edu.
}

States annually (Nortje and Menon, 2004; Rondina et al., 2005). Primary brain damage that occurs at the time of TBI frequently develops long-lasting white matter injury (WMI) that includes traumatic axonal injury, loss of myelin sheath, and inhibition of oligodendrocyte maturation, and it contributes to motor, cognitive, behavioral, and psychiatric deficits including depression and anxiety like-disorders (Hiott and Labbate, 2002; Jorge et al., 2004; Johnson et al., 2013; Dent et al., 2015; McKee and Lukens, 2016), 
However, the underlying mechanisms of TBI-induced WMI and its correlation with anxiety and depressive behavior remain poorly understood.

Both human studies and experimental models of TBI indicate that TBI induces a complex array of inflammatory responses in the acute post-injury phase, in association with the infiltration of $\mathrm{T}$ cells, macrophages, leukocytes, and natural killer (NK) cells (Holmin et al., 1995; Soares et al., 1995; Carlos et al., 1997; Holmin et al., 1998; Holmin and Mathiesen, 1999; Stahel et al., 2000; X. H. Chen et al., 2004). Consistent with studies investigating pathological changes in injured postmortem human brains (Gentleman et al., 2004; Johnson et al., 2013), several studies reported that resident, resting microglia in rodents undergo both morphological and expressive changes following injury (Aihara et al., 1995; Gentleman et al., 2004; Wilson et al., 2004; Maxwell et al., 2006; Nagamoto-Combs et al., 2007) and contribute to the multitude of cytokines associated with post-traumatic inflammatory cascades (Loane and Byrnes, 2010; Ziebell and MorgantiKossmann, 2010). As a part of the mechanism, it is reported that after TBI, microglia are rapidly activated and polarized to the M1 phenotype, releasing high levels of proinflammatory cytokines (IL- $1 \beta$, TNF- $\alpha$, IL6, etc.), that, in turn, hinders axonal regeneration and oligodendrocyte maturation (Lampron et al., 2015; Y. Chen et al., 2017; Qin et al., 2017). In contrast, polarization of microglia with the M2 phenotype typically release restorative cytokines and growth factors (TGF- $\alpha$, IL-10, BDNF, GDNF), clear tissue debris through phagocytosis and promote remyelination (Olah et al., 2012; Xu et al., 2015; Zhao et al., 2015; Schafer et al., 2016). It is considered that M1/M2-type microglia/macrophages necessarily direct T-helper cells toward T-helper 1 (Th1)- or Th2like activities, respectively (Mills and Ley, 2014). The Th1 lymphocytes, which secrete proinflammatory cytokines such as interferon (IFN)- $\gamma$ or TNF- $\alpha$ and Th2 lymphocytes, which produce anti-inflammatory cytokines such as IL-4 and IL-10 may also play crucial roles in the post-injury neurodegeneration or recovery of the CNS (Jin and Yamashita, 2016). However, the precise molecular mechanisms and dynamics of microglial activation/phenotypic changes and T-cell infiltration and their role in TBI-mediated WMI are not clear.

An increasing amount of evidence points toward the central roles of type 1 IFN signaling in inflammatory CNS disorders and age-related cognitive decline (Taylor et al., 2014). Type-1 IFNs bind to and activate the IFN receptor (IFNAR), leading to signaling through the canonical JAK-STAT pathway, resulting in the upregulation of type-1 IFNs (Dai et al., 2011). Type I IFNs are a large subgroup of interferon proteins, including IFN $\alpha$ and IFN $\beta$, that help regulate the activity of the immune system by inducing the recruitment of immune cell to sites of infection and enhance the effector functions of T, NK, and B cells and macrophages. Recent evidence indicates that brain trauma in humans promotes enhanced expression of type-1 IFN, which suggests that type-1 IFN signaling may potentially influence clinical outcome in TBI patients (Karve et al., 2016). Lately, it was shown that expression of endoplasmic reticulum (ER) protein, stimulator of interferon genes (STING), had significant upregulation in late trauma human brain samples and mouse models of TBI and it could mediate the type-I IFN production and neuroinflammatory response after TBI (Abdullah et al., 2018). However, the mechanism of type-1 IFN signaling induction and its consequences on both WMI and neurobehavioral outcome after TBI remain unclear.

ER stress and abnormal protein accumulation are detected in the pericontusional brain following TBI and are considered an important mechanism of secondary injury after TBI (Hood et al.,
2018; Tan et al., 2018). Recently, we have shown that activation of protein kinase $\mathrm{R}$ (PKR)-like ER kinase (PERK) or PERKphosphorylation mediates the unfolded protein response signaling pathway that predominates following TBI. Blocking the aberrant activation of PERK by GSK2656157 resulted in an improvement in synaptic plasticity and puncta after TBI (Sen et al., 2017). However, it is not clear whether the consequences of TBIinduced ER stress are associated with neuroinflammation, the extent of WMI, and the development of depression and anxiety disorders. Recent research has documented that ER stress can cause the translocation of STING from the outer membrane ER to the cytoplasm, where STING recruits TANK-binding kinase 1 (TBK1), which phosphorylates STING and the transcription factor interferon regulatory factor 3 (IRF3) to induce type-I IFNs and other cytokines (Y. P. Liu et al., 2012; Tanaka and Chen, 2012; Petrasek et al., 2013; Cai et al., 2014; S. Liu et al., 2015; Cui et al., 2016).

In the present study, we show that neuronal ER stress induced activation of the neuronal STING signaling cascade could regulate microglia phenotype/activation and T-cell-mediated innate and adaptive inflammatory immune signaling leading to WMI and depression/anxiety-like disorders following TBI. Blocking PERK mediated neuronal ER stress through the administration of GSK2656157 can block this inflammatory cascade by preventing the induction of neuronal IFN $\beta$, and subsequent microglial polarization to M1 phenotype, and Th1 infiltration leading to a reduction in WMI, and improvement in neurobehavioral outcomes following TBI.

\section{Materials and Methods}

TBI procedure. The Committee on Animal Use for Research and Education at the University of Pittsburgh approved all animal studies, in compliance with National Institutes of Health guidelines. TBI was elicited by unilateral controlled cortical impact (CCI), as previously described (Fox et al., 1998) with little modification (Farook et al., 2013; Kapoor et al., 2013; Sen and Sen, 2016; Saha et al., 2018). Briefly, 8- to 10-week-old adult male or female C57BL/6 mice (The Jackson Laboratory) were randomly assigned to the CCI or sham injury group for all the experiments. Animals were anesthetized with xylazine $(8 \mathrm{mg} / \mathrm{kg}) / \mathrm{ketamine}(60 \mathrm{mg} / \mathrm{kg})$ and subjected to a sham injury or CCI. Mice were placed in a stereotaxic frame (Leica Microsystems, 39463920-Impact one stereotaxic Impactor$\mathrm{CCI}$ ), and mice were impacted at $4.5 \mathrm{~m} / \mathrm{s}$ with a $20 \mathrm{~ms}$ dwell time and 1.2 $\mathrm{mm}$ depression using a 3-mm-diameter convex tip, mimicking a moderate TBI. Sham-operated mice underwent identical surgical procedures but were not impacted. The incision was closed with $3 \mathrm{M}$ Vet bond tissue adhesive and mice were allowed to recover on the heat pad. Body temperature was maintained at $37^{\circ} \mathrm{C}$ using a small animal temperature controller throughout all procedures (Kopf Instruments). For treatments selective PERK inhibitor GSK2656157 (Cayman Chemical; 10, 20, or 50 $\mathrm{mg} / \mathrm{kg}$ bodyweight, dissolved in DMSO) were intraperitoneally administered at $30 \mathrm{~min}$ post-TBI, followed by a daily dose for $3 \mathrm{~d}$ or 3 weeks according to the experiment. Because GSK2656157 was dissolved in DMSO, only sham and TBI mice received DMSO as controls. For behavioral assay with isoflurane, mice were anesthetized with $4 \%$ isoflurane in air or oxygen during the induction, and $2.5 \%$ isoflurane was maintained during the surgery through an induction chamber using a nose cone, using a flow rate of 1-1.5 L oxygen per minute (Fox et al., 1998). Depth of anesthesia was evaluated by checking respiration rate and palpebral and pedal-withdrawal reflexes. Under anesthesia, mouse heads were stabilized in a stereotaxic frame, and a skin incision was made under aseptic conditions to expose the skull and bregma for TBI.

Intranasal delivery of CXCL10-siRNA and PERK-siRNA. CXCL10siRNA or PERK-siRNA (Santa Cruz Biotechnology) were administered to 8- to 10-week-old C57BL/6J mice through an intranasal route using in vivo JetPEI (Polyplus) transfection reagent as described previously with modifications (Bitko and Barik, 2008; Rodriguez et al., 2017; Saha et al., 
2018). The siRNA-JetPEI complex was prepared according to the manufacturer's protocol with modifications (Bitko and Barik, 2008; Rodriguez et al., 2017; Saha et al., 2018). Briefly, either the CXCL10 siRNA or PERK siRNA or control siRNA along with JetPEI were separately diluted into half the injection volume in a $10 \%$ sterile glucose solution where the final glucose concentration would have to be $5 \%$. This formulation corresponds to nitrogen to phosphate ratio of 7 . Both the solutions were mixed by slight vortexing, and the JetPEI-RNAi mixture was incubated $15 \mathrm{~min}$ at room temperature. Intranasal administration of the Jet-PEI complex was performed $30 \mathrm{~min}$ after either sham or TBI surgery with the pipette tip to each nostril of the mouse when animals were under anesthesia. A $5 \mu$ l of the JetPEI-RNAi complex was slowly administered to the nostrils maintaining a $2-3 \mathrm{~s}$ interval up to $10 \mu \mathrm{l}$ total/nostril of a mouse. After 5-10 s, another $10 \mu 1$ of the solution was administered to the other nostril following a similar way for a total of $20 \mu \mathrm{l} /$ mouse and $10 \mu \mathrm{g}$ of siRNA per mouse. Mice were under observation until the entire solution disappeared through the nasal cavity and the mice regained consciousness.

Primary neuron culture. Primary cortical neurons were prepared from E16-E19 mouse embryos that have been described previously (Hilgenberg and Smith, 2007; Lopez-Fabuel et al., 2016; Berl et al., 2017; Fu et al., 2019) with some modifications. Briefly, embryos were dissected out from anesthetized pregnant mouse, decapitated and the brain tissue was immediately transferred to dissecting solution ( $43.8 \mathrm{~mm}$ sucrose, $33.3 \mathrm{~mm}$ $\mathrm{D}(+)$ glucose, $6.85 \mathrm{~mm} \mathrm{NaCl}, 0.27 \mathrm{mM} \mathrm{KCl}, 8.5 \mu \mathrm{M} \mathrm{Na} \mathrm{NPO}_{4}, 11 \mu \mathrm{M}$ $\mathrm{KH}_{2} \mathrm{PO}_{4}$, and $0.28 \mathrm{~mm}$ HEPES, $\mathrm{pH}$ 7.4). After removing the cerebellum and meninges, neocortices were carefully dissected out and dissociated using Neuronal Tissue Dissociation Kit (P) followed by cell separation using the Neuron Isolation Kit (mouse; Miltenyi) according to the manufacturer's protocol (MACS technology). The identity of the isolated fractions was confirmed by Western blotting against neuronal [neuronspecific class III $\beta$-tubulin (TUJ1) and MAP2]- or astrocytic (GFAP)specific markers. The cell pellet was resuspended in fresh medium and seeded onto coverslips of 6-well plates at a density of $1.5 \times 10^{5}$ cells on $1 \times$ poly-D-lysine-coated (PDL; Sigma-Aldrich) coverslips for immunofluorescence studies and, a high density of $2-3 \times 10^{6}$ cells in $6 \mathrm{~cm}$ coated dishes for Western blot and biochemical assay. Cells were maintained in complete media with Neurobasal Plus media supplemented with 1XB27 Plus, L-glutamine and 1\% Penstrep solution (Invitrogen/ThermoFisher Scientific, USA) at $37^{\circ} \mathrm{C}$ and $5 \% \mathrm{CO}_{2}$ and one-third of the medium was replaced every $4 \mathrm{~d}$. Neurons were treated with ER stress inducer tunicamycin (3 $\mu \mathrm{g} / \mathrm{ml}$; Santa Cruz Biotechnology), PERK inhibitors GSK2656157 (15 $\mu \mathrm{g} / \mathrm{ml}$; Cayman Chemical), and/or IFN $\beta$ (100 U/ml; R\&D Systems) for $24 \mathrm{~h}$ at $37^{\circ} \mathrm{C}$. Following treatment, the culture medium was stored for ELISA assays, and cells were used for immunocytochemistry or Western blot or immunoprecipitation analysis.

The cultured neurons were transfected with IFN $\beta$ siRNA following the Polyplus transfection reagent protocol (Interferin siRNA transfection reagent; Sen et al., 2018). Briefly, 8.4 ng of IFN $\beta$ siRNA duplex (Santa Cruz Biotechnology) was mixed into $100 \mu \mathrm{l}$ of sera-free medium and then thoroughly mixed with $2 \mu \mathrm{l}$ of Interferin transfection reagent by vortexing for $10 \mathrm{~s}$. The mixture was incubated $10 \mathrm{~min}$ at room temperature for transfection complex formation. Cells in a 24-well plate were changed with $500 \mu \mathrm{l}$ of complete medium, and the transfection complex was added to achieve a final concentration of $1 \mathrm{~nm}$ of IFN $\beta$ siRNA. The media was changed after $24 \mathrm{~h}$ and incubated for an additional $48 \mathrm{~h}$ before collecting the media for other experiments and fixing the cells for coimmunocytochemistry.

Primary microglia culture. Microglia culture was prepared from 0 to 3-d-old mouse pups following previous protocol (Lian et al., 2016) with some modifications. In brief, pups were anesthetized on ice and, the cortices were isolated, minced, and treated with $1 \%$ trypsin at $37^{\circ} \mathrm{C}$ for 20 $\mathrm{min}$. After the trypsin digestion, a single-cell suspension was prepared in complete media [DMEM-Ham's F-12 medium supplemented with $2 \mathrm{~mm}$ L-glutamine, $1 \mathrm{~mm}$ sodium pyruvate, non-essential amino acids $1 \times, 10 \%$ fetal bovine serum (FBS), and 1\% Penstrep solution all from Invitrogen, Thermo Scientific] by gentle trituration with fire-polished glass Pasteur pipette. After passing through $70 \mu$ nylon mesh, cells were counted and seeded in a $1 \times$ PDL-coated T75 flask at a density of 50,000 cells $/ \mathrm{cm}^{2}$ and maintained at $37^{\circ} \mathrm{C}, 5 \% \mathrm{CO}_{2}$, and $95 \%$ air (ThermoFisher Scientific, 3110). Media was changed twice a week. Following 10-14 d of incubation, microglia were removed from the astroglia layer by shaking the flasks on an orbital shaker (Labnet, Orbit P4) for $2 \mathrm{~h}$ at $250 \times \mathrm{g}$. The microglial pellets were resuspended in the complete DMEM medium and seeded on the poly-D-lysine-coated glass coverslips in 6-well plates (4$5 \times 10^{5}$ cells/well $)$ or on $35 \mathrm{~mm}$ glass-bottom dishes $\left(4-5 \times 10^{5}\right.$ cells/ dish). Experiments were performed on Days $2-3$ after seeding. After 2-3 $\mathrm{d}$ of seeding, cells were treated with IFN $\beta$ (100 U/ml; R\&D Biosystems) with or without GSK2656157 (15 $\mu \mathrm{g} / \mathrm{ml})$ or neuronal conditional media for $24 \mathrm{~h}$ at $37^{\circ} \mathrm{C}$. After treatment, cell media was saved for ELISA assay and cells were either fixed with 4\% PFA for immunocytochemistry or lysed for Western blot analysis.

Western blot and co-IP. The pericontusional cortex was isolated and, lysates were prepared as described before to perform Western blot (WB) and coimmunoprecipitation (co-IP; Farook et al., 2013; Kapoor et al., 2013; Sen and Sen, 2016; Saha et al., 2018). Blots were incubated overnight at $4^{\circ} \mathrm{C}$ in primary antibody for phospho and total-PERK (Abcam; 1:500), phospho-IRF3 (Cell Signaling Technology; 1:500), phospho-TBK1 (Cell Signaling Technology; 1:500), TBK1 (Santa Cruz Biotechnology; 1:500), phospho-NFкB p65 (Ser 536; (zcomSanta Cruz Biotechnology; 1:500 dilution), phospho-Stat3 (Santa Cruz Biotechnology; 1:500 dilution), phospho-Stat6 (Santa Cruz Biotechnology; 1:500 dilution), phosphoStat1 (Santa Cruz Biotechnology; 1:500 dilution), STING (Millipore; 1:500 dilution), STING (Phospho-Ser366; Affinity Biosciences; 1:500 dilution), or Actin (Sigma-Aldrich; 1:5000 dilution) followed by incubation with a LI-COR IRDye secondary antibody at room temperature. The detailed information about the antibodies used for the Western blot analysis is included in Table 1. Blots were visualized using an LI-COR Odyssey imager, and ImageJ software was used to determine the intensity of each band, and the changes in the band-intensity were represented as a fold-change as described previously (Farook et al., 2013; Kapoor et al., 2013; Sen and Sen, 2016; Saha et al., 2018). For Co-IP, cortex collected from all set of experiments were homogenized in lysis buffer [50 mM Tris, pH 7.4, $150 \mathrm{~mm} \mathrm{NaCl}, 0.5 \%$ (v/v) Tween 20, 50 mм Tris, pH 7.5, 1 mм EDTA with protease and phosphatase inhibitor] by passage through a 26-gauge needle, and $400 \mu \mathrm{g}$ of the total protein for each sample were incubated overnight with STING (Millipore; 1:100) antibody for overnight. The immune-precipitates were resolved and analyzed by Western blotting with TBK-1 antibody.

Immunohistochemistry and immunocytochemistry. The immunohistochemistry (IHC) was performed per our method as described previously (Farook et al., 2013; Kapoor et al., 2013; Sen and Sen, 2016; Saha et al., 2018). Immediately following euthanasia, mice were transcardially perfused with 0.1 м PBS, pH 7.4, followed by $4 \%$ paraformaldehyde (over 10 $\mathrm{min}$ ). The brain was harvested, postfixed in $4 \%$ paraformaldehyde for $2 \mathrm{~h}$, and sequentially immersed in $15 \%$ and then $30 \%$ sucrose in PBS and $0.1 \% \mathrm{NaN}_{3}$ (Sigma-Aldrich), pH 7.4, overnight. Brain samples were subjected to cryosectioning ( $25 \mu \mathrm{m}$ thickness) and for immunofluorescence (IF) analysis sections were incubated 40 min with $0.1 \%$ Triton X-100 in PBS, subsequently blocked for $1 \mathrm{~h}$ with $10 \%$ normal goat serum containing $0.1 \%$ Triton $\mathrm{X}-100$ at room temperature, followed by overnight incubation at $4^{\circ} \mathrm{C}$ with the primary antibody against STING (PhosphoSer366; Affinity Biosciences; 1:100 dilution), IFN $\beta$ (1:100; Santa Cruz Biotechnology), phospho-IRF3 (1:100; Cell Signaling Technology), p-NF- $\kappa$ B p65 (Ser 536; 1:100; Santa Cruz Biotechnology), phosphoTBK1 (1:100; Cell Signaling Technology), CD206 (1:100; Santa Cruz Biotechnology), CD16/32 (1:100; Santa Cruz Biotechnology), CXCL10 (1:100; Santa Cruz Biotechnology), myelin basic protein (MBP; 1:100; Santa Cruz Biotechnology), Iba-1 (1:1000; Wako), NeuN (1:250; Millipore), NF200 (1:100; Sigma-Aldrich), and/or MAP2 (1:250 dilution; Novus). The detailed information about the antibodies used for IF staining with corresponding references is included in Table 1. Sections were then washed three times with PBS and incubated with the appropriate AlexaFluor-tagged secondary antibody for $3 \mathrm{~h}$ at room temperature in the dark. Sections were then washed three times with PBS and mounted with Prolong Gold anti-fade mounting media with DAPI (Invitrogen). The analysis was performed in a blinded manner with ImageJ software (NIH) using the regions-of-interest (ROI) tool. Colocalization analysis 
Table 1. Sources and concentrations of primary antibodies used in this study for immunoblotting/immunofluorescence/immunoprecipitation

\begin{tabular}{|c|c|c|c|c|c|}
\hline Primary antibody target & Source & Catalog\#. (Host) & $\begin{array}{l}\text { Application } \\
\text { (dilution) }\end{array}$ & Reference, DOI & Immunogen and reactivity \\
\hline \multirow[t]{2}{*}{$\begin{array}{l}\text { NF-H, Non-phosphorylated } \\
\text { (SMI 32) }\end{array}$} & \multirow[t]{2}{*}{ BioLegend } & \multirow[t]{2}{*}{801702 (Mouse) } & \multirow[t]{2}{*}{ IF $(1: 200)$} & https://doi.org/10.1523/JNEUROSCI.2475-10.2011 & $\begin{array}{l}\text { Non-phosphorylated epitope in neurofilament } \mathrm{H} \text { of mam- } \\
\text { malian species }\end{array}$ \\
\hline & & & & https://doi.org/10.1523/JNEUROSCI.5837-09.2010 & Reactivity: mouse, rat, and human \\
\hline \multirow[t]{2}{*}{ lba-1 } & \multirow[t]{2}{*}{ Wako Chemicals } & \multirow[t]{2}{*}{ 019-19741 (Rabbit) } & \multirow[t]{2}{*}{ IF $(1: 1000)$} & $\begin{array}{l}\text { https://doi.org/10.1186/s12974-015-0270-3, } \\
\text { https://doi.org/10.4049/jimmunol.1401459, } \\
\text { https://doi.org/10.1016/j.celrep.2018.09.052, } \\
\text { https://doi.org/10.1038/s41467-018-03496-2 }\end{array}$ & Synthetic peptide corresponding to C-terminus of Iba1 \\
\hline & & & & & Reactivity: mouse and other \\
\hline NEUROFILAMENT 200 & Sigma-Aldrich & $\begin{array}{l}\text { N4142 } \\
\text { (Rabbit) }\end{array}$ & IF $(1: 200)$ & https://doi.org/10.1038/s41467-018-03496-2 & $\begin{array}{l}\text { Neurofilament } 200 \text { from the bovine spinal cord } \\
\text { Reactivity: mouse and other }\end{array}$ \\
\hline p-Stat1 & \multirow[t]{2}{*}{ Santa Cruz Biotechnology } & sc-8394 & IF $(1: 100)$ & https://doi.org/10.1002/ijc.30398 & full-length Stat1 of human origin \\
\hline$(A-2)$ & & (Mouse) & $\mathrm{IB}(1: 500)$ & $\begin{array}{l}\text { https://doi.org/10.1186/s13046-018-0792-5 } \\
\text { https://doi.org/10.1038/jcbfm.2015.169 }\end{array}$ & Reactivity: mouse, rat, and human \\
\hline p-Stat6 (pY641.18) & Santa Cruz Biotechnology & sc-136019 (Mouse) & $\mathrm{IB}(1: 500)$ & https://doi.org/10.1016/j.molimm.2011.10.009 & $\begin{array}{l}\text { Short amino acid sequence containing phosphorylated Tyr } \\
641 \text { of Stat6 of human origin Reactivity: mouse and } \\
\text { human }\end{array}$ \\
\hline \multirow{2}{*}{$\begin{array}{l}\text { p-Stat3 } \\
\text { (B-7) }\end{array}$} & \multirow[t]{2}{*}{ Santa Cruz Biotechnology } & \multirow[t]{2}{*}{ sc-8059 (Mouse) } & \multirow[t]{2}{*}{ IB $(1: 500)$} & \multirow{4}{*}{$\begin{array}{l}\text { https://doi.org/10.1016/j.neuro.2018.03.003 } \\
\text { https://doi.org/10.1038/nature25741 } \\
\text { https://doi.org/10.1016/j.brainresbull.2019.05.016 }\end{array}$} & Between amino acids $659-709$ of Stat 3 of human origin \\
\hline & & & & & Reactivity: mouse, rat, and human \\
\hline CD206 & \multirow[t]{2}{*}{ Santa Cruz Biotechnology } & \multirow[t]{2}{*}{ sc-58986 (Mouse) } & \multirow[t]{2}{*}{ IF $(1: 100)$} & & full-length CD206 of human origin \\
\hline$(15-2)$ & & & & & Reactivity: mouse, rat and human \\
\hline \multirow[t]{2}{*}{ p-NF $\kappa$ B p65 (27.Ser 536) } & \multirow[t]{2}{*}{ Santa Cruz Biotechnology } & \multirow[t]{2}{*}{ sc-136548 (Mouse) } & $\mathrm{IB}(1: 500)$ & \multirow[t]{2}{*}{ https://doi.org/10.1007/s12035-019-1512-7 } & $\begin{array}{l}\text { Short amino acid sequence containing Ser } 536 \text { phosphory- } \\
\text { lated NF } \kappa \text { B p } 65 \text { of human origin }\end{array}$ \\
\hline & & & IF $(1: 100)$ & & Reactivity: mouse, rat, and human \\
\hline CD16 (ASH 1975) & Santa Cruz Biotechnology & sc-52376 (Mouse) & IF $(1: 100)$ & $\begin{array}{l}\text { https://doi.org/10.1016/j.brainresbull.2019.05.016 } \\
\text { https://doi.org/10.1016/j.neuropharm.2018.09.015 }\end{array}$ & $\begin{array}{l}\text { raised against whole cells of human origin } \\
\text { Reactivity: mouse, rat, and human }\end{array}$ \\
\hline IFN- $\beta$ (7F-D3) & Santa Cruz Biotechnology & sc-57201 (Rat) & IF $(1: 100)$ & https://doi.org/10.1016/j.imbio.2015.05.013 & IFN- $\beta$ of mouse origin; reactivity: mouse \\
\hline IP-10 & Santa Cruz Biotechnology & sc-374092 & IF $(1: 100)$ & https://doi.org/10.4049/jimmunol.1401459 & $\begin{array}{l}\text { Specific for an epitope mapping between amino acids } \\
24-55 \text { within an internal region of IP- } 10 \text { of mouse } \\
\text { origin }\end{array}$ \\
\hline$(\mathrm{E}-2)$ & & (Mouse) & & & Reactivity: mouse \\
\hline STING (Phospho-Ser366) & Affinity Biosciences & AF7416 (Rabbit) & IF $(1: 200)$ & https://doi.org/10.1126/science.aaa2630 & $\begin{array}{l}\text { A synthesized peptide derived from human STING around } \\
\text { the phosphorylation site of Ser } 366 \text {. } \\
\text { Reactivity: mouse, rat, and human }\end{array}$ \\
\hline STING & MilliporeSigma & MABF270 (Mouse) & WB & https://doi.org/10.1101/493098 & $\begin{array}{l}\text { His-tagged recombinant human STING C-terminal cyto- } \\
\text { plasmic domain fragment (amino acids 301-315) }\end{array}$ \\
\hline & & & $(1: 500)$ & & Reactivity: mouse and human \\
\hline & & & $\begin{array}{l}\text { IP } \\
(1: 100)\end{array}$ & & \\
\hline NeuN & MilliporeSigma & ABN90 & IF $(1: 200)$ & https://doi.org/10.1038/s41467-018-03496-2 & $\begin{array}{l}\text { GST-tagged recombinant protein corresponding to the } \\
\text { N-terminus of mouse NeuN }\end{array}$ \\
\hline & & (Guinea Pig) & & & Reactivity: mouse and rat \\
\hline Map2 & Novus Biologicals & NB300-213 (Chicken) & IF $(1: 200)$ & https://doi.org/10.1016/j.neuron.2018.10.008 & $\begin{array}{l}\text { Recombinant human construct of projection domain se- } \\
\text { quences, amino acids 377-1505 }\end{array}$ \\
\hline & & & & & Reactivity: mouse, rat, and human \\
\hline p-PERK & Abcam & ab192591 (Rabbit) & IB $(1: 1000)$ & https://doi.org/10.1523/JNEUROSCI.2343-16.2017 & $\begin{array}{l}\text { A synthetic peptide corresponding to human PERK aa } \\
\text { 976-988 (phospho T982) }\end{array}$ \\
\hline (phospho T982) & & & IF $(1: 100)$ & https://doi.org/10.3892/ijmm.2018.3486 & Sequence:(c)PAYARHTGQVGTK \\
\hline & & & & & Reactivity: Mouse, rat, and human \\
\hline PERK & Abcam & ab79483 (Rabbit) & IB $(1: 1000)$ & https://doi.org/10.1523/JNEUROSCI.2343-16.2017 & $\begin{array}{l}\text { A synthetic non-phospho-peptide derived from human } \\
\text { PERK around the phosphorylation site of threonine } 981 \\
\text { (RHTPGQ) Reactivity: mouse, rat, and human }\end{array}$ \\
\hline & & & $\mathbb{I P}(1: 100)$ & https://doi.org/10.3892/ijmm.2018.3486 & \\
\hline
\end{tabular}

IF, Immunofluorescence; IP, immunoprecipitation; and IB, immunoblotting.

was performed using the "Pearson-Spearman correlation colocalization" ImageJ plug-in across ROI within the image. Microglia stained with anti-Iba- 1 was used to measure the total perimeter of individual microglial cells using ImageJ software (NIH) by counting the number of pixels surrounding the cell. Eight sections per sample were analyzed per group, and the mean perimeter of microglial cells was calculated (HernandezRabaza et al., 2015). For fluorescent myelin (FM) staining brain sections were incubated with FluoroMyelin Red (Invitrogen; 1:300) for $30 \mathrm{~min}$ at room temperature, washed with PBS before mounting. Imaging was performed at $20 \times$ magnification with the inverted Olympus fluorescent microscope (IX83) equipped with a digital camera, and appropriate filters for DAPI, Alexa 488, CY3, and CY5 and equipped with FluoView software (Olympus America). The ratio of NF200 to MBP fluorescence intensity was quantified, as described previously (Moore et al., 2014). In brief, two ROIs in the pericontusional cortex (CX), and external capsule (EC) were randomly selected and captured using the same imaging parameters. Images were analyzed by an investigator blinded to experimental groups with ImageJ software. Fluorescence intensity was calculated as the percentage of fluorescence-positive pixels within each ROI. Corpus callosum (CC) thickness was measured on coronal sections in each brain at three different locations, and the mean thickness of the CC was determined. For immunocytochemistry, cells were fixed in 4\% PFA for $20 \mathrm{~min}$ and stained with appropriate antibodies as described above.

ELISA. Primary culture supernatants and pericontusional tissue lysates were analyzed for cytokine production by using ELISA kits (R\&D 
Systems, Invitrogen) manufactured with IFN $\beta$, IFN $\alpha$, CXCL10, CXCL5, and CXCL11 (Balachandran et al., 2004; Fenwick et al., 2015). The supernatant of primary neuronal culture treated with tunicamycin was used to measure for IFN $\beta$, and IFN $\alpha$ level and the supernatant of primary microglia cultures treated with IFN $\beta$ were measured for CXCL10, CXCL11, and CCL5 levels (Fenwick et al., 2015). The assays were conducted following the manufacturer's and previously published protocol (Zhu et al., 2017) with minor modifications and the absorbance were measured with a microplate reader (BioTek Systems) at $450 \mathrm{~nm}$.

Quantitative real-time PCR. Quantitative real-time PCR (qRT-PCR) was performed per our method (Sen and Sen, 2016). Total RNA was isolated using the kit (QIAGEN) and the cDNA was subjected to qRTPCR analysis with fast-standard SYBR green dye (Applied Biosystems) using an AB7500 RT-PCR instrument (Applied Biosystems). Results were normalized using total input DNA and expressed as bound/input (fold). Pericontusional cortex tissues were taken $3 \mathrm{~d}$ post-TBI. The primers used to carry out PCR analysis are purchased from realtimeprimers.com are as follows:

IFN $\beta$ : Forward-5'GCAGCTGAATGGAAAGATCA-3',

Reverse-5'GTGGAGAGCAGTTGAGGACA-3';

IFN $\alpha$ : Forward-5'CACTCCTGGTACAAATGAGG-3',

Reverse-5'AGCAGATGAGTCCTTTGATG-3';

Ccl5: Forward-5'CAATCTTGCAGTCGTGTTTG-3',

Reverse-5'GGAGTGGGAGTAGGGGATTA-3';

Cxcl10: Forward-5'CAAAAGTAACTGCCGAAGCA-3',

Reverse-5'CTGAGCTAGGGAGGACAAGG-3';

Cxc19: Forward-5'ACTTCTGAGGCTCACGTCAC-3',

Reverse-5' AGGTTCTGAAGGCCAACTCT-3';

TNF- $\alpha$ : Forward-5'TGTCCCTTTCACTCACTGGC-3',

Reverse-5'CATCTTTTGGGGGAGTGCCT-3';

IL6: Forward-5'GGGACTGATGCTGGTGACAA-3',

Reverse-5'CCACGATTTCCCAGAGAACA-3';

IL1 $\beta$ : Forward-5' GCCCATCCTCTGTGCTCA-3',

Reverse-5' AGGCCACAGGTATTTTGTC-3';

IL12: Forward-5' -CGCAGCACTTCAGAATCACA-3',

Reverse-5'TCTCCCACAGGAGGTTTCTTG-3';

IL10: Forward-5'GCTCTTACTGACTGGCATGAG-3',

Reverse-5'CGCAGCTCTAGGAGCATGTG-3';

TGF $\beta$ : Forward 5' -GGAGAGCCCTGGATACCAAC-3',

Reverse-5' -CAACCCAGGTCCTTCCTAAA-3';

Ccr7: Forward-5'ACGACAGCCAAAAGTGAAAG-3',

Reverse-5'GCTCTGTGGGAGCATTTAGA-3';

Cd163: Forward-5'CCAAGCTGTGAAGGCACTAAA-3',

Reverse-5'ACGGTTTGGCAGGACAATC-3';

Mrc1 (Cd206): Forward-5'CTCGTGGATCTCCGTGACAC-3',

Reverse-5'GCAAATGGAGCCGTCTGTGC-3';

IL13: Forward-5'CTACAGCTCCCTGGTTCTCT-3',

Reverse-5'TTGCTCAGCTCCTCAATAAG-3';

IL4: Forward-5'CAAGGTGCTTCGCATATTTT-3',

Reverse-5'ATCCATTTGCATGATGCTCT-3';

Actin: Forward-5' -AAGAGCTATGAGCTGCCTGA3',

Reverse-5'TACGGATGTCAACGTCACAC-3'.

Product specificity was confirmed by melting curve analysis. Gene expression levels were quantified and, data were normalized to actin, a housekeeping gene. Data are expressed as mean fold-change versus control or sham group.

Preparative and analytical flow cytometry (fluorescence-activated cell sorting). PBS perfused freshly harvested brain tissue was sieved through a $100 \mu \mathrm{m}$ cell strainer (BD Biosciences), followed by centrifugation $(300 \times$ $g, 5 \mathrm{~min}$ ) to prepare single-cell suspensions. Mononuclear cells were collected after layering it on 30/70\% Percoll (GE Healthcare) gradient solution and centrifugation at $400 \times \mathrm{g}$ for $30 \mathrm{~min}$ to remove myelin. Brain cells were then collected from the middle layer and washed twice with PBS containing 2\% FBS (Pino and Cardona, 2011). Cell viability was checked using Trypan blue (Sigma-Aldrich). Viable cells were counted, and $10 \times 10^{6}$ cells were used for flow cytometry. CNS mononuclear cells were incubated 10-15 min with the anti-Fc receptor (Clone 2.4G2; 1 $\mu \mathrm{g} / \mathrm{ml}$; BD Pharmingen) in PBS with $2 \%$ FBS on ice. CNS mononuclear/ microglia cells were stained at $4^{\circ} \mathrm{C}$ in the dark with antibodies against the cell surface markers CD11b, F4/80, CD86, CD206, CD45, CD4, and/or CD3 (All antibodies purchased from eBioSciences) in PBS with $2 \%$ FBS (J. Wang et al., 2017). Cells were then rinsed with PBS-2\% FBS by centrifugation for $3 \mathrm{~min}$ at $300 \times \mathrm{g}$, and pellets were resuspended in PBS with $2 \%$ FBS before flow cytometry analysis. For intracellular staining, following a PBS wash, cells were fixed and permeabilized using a Fixation/ Permeabilization buffer (Affymetrix, eBioscience), and then incubated with antibodies for intracellular labeling of Foxp3, Tbet, and GATA3 (all from eBioSciences) in permeabilization buffer (Yu et al., 2015). After a final wash in PBS $2 \%$ FBS, cells were analyzed using a 6-color flow cytometer (CytoFLEX, Beckman Coulter), and CytExpert software, as described previously (Matveeva et al., 2018). Isotype-matched controls were analyzed to set the appropriate gates for each sample. In each experiment, at least 10,000 events were recorded from each sample for analysis. For each marker, samples were analyzed in duplicate. After excluding doublets (FSC-H, FSC-W, and SSC-H, SSC-W) and dead cells, CNS cell populations were gated based on isotype control antibodies as $\mathrm{CD} 45^{\text {low }} \mathrm{CD} 11 \mathrm{~b}{ }^{+}$(microglia) or $\mathrm{CD} 45^{+} \mathrm{CD} 3{ }^{+} \mathrm{CD} 4{ }^{+}$(CD4 T cell). Cells expressing a specific marker were reported as a percentage of the number of gated events.

Ex vivo DTI. Ex vivo diffusion tensor imaging (DTI) was performed to assess white matter integrity in the CC and EC area as previously described (Xia et al., 2018; Yin et al., 2018). Perfusion fixed brains (in 4\% PFA) were maintained in the skull and imaged using a Bruker AV3HD 11.7 tesla/89 mm vertical-bore micro-imaging system equipped with a Micro2.5 gradient set capable of $1500 \mathrm{mT} / \mathrm{m}$, a $20 \mathrm{~mm}$ quadrature RF resonator and ParaVision 6.0.1 (Bruker Biospin). In this procedure, a DTI dataset covering the entire brain was collected using a multi-slice spin-echo sequence with $5 \mathrm{~A} 0$ images and 30 non-co-linear diffusionweighted images with the following parameters: TR/TE 2800/22 ms, 2 averages, $160 \times 160$ matrix, $16 \times 16 \mathrm{~mm}$ field-of-view, 25 slices, $0.5 \mathrm{~mm}$ slice thickness, $b$ value $=3000 \mathrm{~s} / \mathrm{mm} 2$, and $\Delta / \delta=11.0 / 5.0 \mathrm{~ms}$. DTI data were analyzed with DSI Studio software (http://dsi-studio.labsolver. org/). Additionally, $\mathrm{T}_{2}$-weighted images were collected using a RARE sequence with the same field-of-view and TR/TE $=4000 / 30 \mathrm{~ms}, 8$ averages, and RARE factor of 4 . DTI and $\mathrm{T}_{2} \mathrm{w}$ image datasets were loaded into DSI Studio, and in a blinded manner, a ROIs were drawn separately both $\mathrm{CC}$ and EC of the ipsilateral hemisphere to determine fractional anisotropy (FA) and radial diffusivity (RD). Directionally-encoded color (DEC), FA, and RD maps were generated by DSI Studio software.

Measurement of volumetric tissue loss. Animals were anesthetized and perfused intracardially with PBS followed by $4 \%$ PFA. Brains were removed and postfixed $4 \mathrm{~h}$ in $4 \%$ PFA, then transferred to a $30 \%$ sucrose solution and stored at $4^{\circ} \mathrm{C}$ until the tissue was submerged. Brains were cut in $30 \mu \mathrm{m}$-thick sections using a cryostat and were stored in a cryoprotectant solution. Six equally-spaced coronal brain sections spanning the injury site were selected and were mounted on polylysine-coated slides and stained for 20 min with $0.1 \%$ cresyl violet (Sigma-Aldrich) dissolved in distilled water and filtered. Slides stained were dehydrated for 2 min using 100, 95, 70, and 50\% ethanol, cleared in xylene for another $2 \mathrm{~min}$, covered with DPX, and coverslipped. Lesion volume was obtained by multiplying the sum of the lesion areas by the distance between 9 and 15 brain sections. The percentage of volumetric tissue loss was calculated by the ratio of the cortical lesion volume in the ipsilateral cortex divided by the entire contralateral cortex volume (Qu et al., 2016).

Forced swim test. The test was conducted using the method of Porsolt et al. (1977) with minor modifications. Briefly, mice were placed inside a 25 $\mathrm{cm}$ glass cylinder (14 cm diameter) containing $20 \mathrm{~cm}$ of water maintained at $24 \pm 2^{\circ} \mathrm{C}$ and were forced to swim for $6 \mathrm{~min}: 2 \mathrm{~min}$ to adapt to the environment and $4 \mathrm{~min}$ to register immobility time (Einat et al., 2001; do Amaral et al., 2013). Their immobility time was recorded. A mouse was considered immobile when it remained floating in the water, without struggling, making only very slight movements necessary to keep its head above water.

Open-field test. Anxiety-like behavior was assessed 2 weeks after TBI using an open-field apparatus divided into a $5 \mathrm{~cm}^{2}$ grid by black lines ( 81 squares in total) as described previously with modifications (Wakade et al., 2010; Aroniadou-Anderjaska et al., 2012; Almeida-Suhett et al., 
2014). Briefly, mice were placed in the center of the open field, and activity was measured and recorded for $5 \mathrm{~min}$. The total movement time and time spent in the center of the open field were analyzed by an investigator who was blinded to experimental conditions.

Tail suspension test. Mice were individually suspended by the tail on a horizontal bar (50 cm from the floor) using adhesive tape placed $\sim 4 \mathrm{~cm}$ from the tip of the tail as described previously with minor modifications (Guida et al., 2017). The duration of immobility was monitored and recorded for $5 \mathrm{~min}$. Immobility time was defined as the absence of escapeoriented behavior. Mice were categorized as immobile when they did not show any body movement, hung wholly, and passively motionless.

Statistical analysis. The biochemical studies, WB, ELISA, Co-IP, RTPCR, confocal analysis, and all behavioral tests were statistically analyzed using one-way ANOVA, and multiple comparisons were performed using the Tukey-Kramer post hoc test $(p<0.05)$ unless noted otherwise. Mean values were calculated for each biochemical experiment $(n=5)$ and each behavioral experiment $(n=10)$, and all the data were depicted as the mean \pm SEM.

\section{Results}

\section{TBI-induced ER stress activates STING signaling to synthesize IFN $\beta$ in neurons}

ER stress is known to be one of the major contributors to TBImediated secondary injuries, and characterized by activation of a trans-membrane PERK, which resides in the ER (Dash et al., 2015; Tan et al., 2018). Previously we have shown that an increase in PERK phosphorylation in the pericontusional CX in the CCI model within $24 \mathrm{~h}$ is mostly responsible for initiating ER stress in mice after TBI (Sen et al., 2017). However, the cells that are primarily responsible for inducing ER stress remains elusive. Confocal analysis using CX showed that phosphorylated-PERK was mostly enriched in neurons as indicated by colocalization of phospho-PERK and a neuronal marker, NeuN, $3 \mathrm{~d}$ after TBI (Fig. $1 A$ and Fig. 1-1 A, B, available at https://doi.org/10.1523/ JNEUROSCI.0718-19.2019.f1-1).

ER stress was shown to cause the translocation of STING into the cytoplasm, where STING recruits TBK1, which phosphorylates STING and the transcription factor IRF3 to induce type-I interferons and other cytokines (Y. P. Liu et al., 2012; Tanaka and Chen, 2012; Petrasek et al., 2013; Cai et al., 2014; S. Liu et al., 2015; Cui et al., 2016). To find out whether TBI-induced ER stress can also activate the STING pathway in neurons, we performed confocal microscopic analysis of phospho-STING (Ser365), phospho-TBK1 (phosphorylation of TBK1 at Ser172, a residue that is important for TBK1 activation), and phospho-IRF3 (phosphorylation of IRF3 at Ser396, which is important for IRF3 activation) along with NeuN in brain sections after TBI with or without a selective inhibitor of PERK phosphorylation, GSK2656157 (50 mg/kg). Our data show that STING phosphorylation in NeuN-positive cells was increased in the pericontusional cortex neurons of TBI mice compared with sham (Fig. $1 B$ and Fig. 1-1C, D, available at https://doi.org/10.1523/JNEUROSCI.0718-19.2019.f1-1); however, phospho-STING expression was dramatically decreased after treatment with GSK2656157 following TBI (Fig. $1 B$ and Fig. 1-1C,D, available at https://doi.org/ 10.1523/JNEUROSCI.0718-19.2019.f1-1). Similar to phosphoSTING, phospho-TBK1 and phospho-IRF3 were also increased after TBI in the CX compared with sham (Fig. $1 C, D$, and Fig. 1-1E-H, available at https://doi.org/10.1523/JNEUROSCI.071819.2019.f1-1). TBI-mediated increase in phospho-TBK1 and phospho-IRF3 was considerably decreased by $3 \mathrm{~d}$ of GSK2656157 treatment following TBI (Fig. $1 C, D$, and Fig. $1-1 E-H$, available at https://doi.org/10.1523/JNEUROSCI.0718-19.2019.f1-1). Considering that a formation of a multimeric complex among STING and TBK1 is necessary for phosphorylation of STING and IRF3 (Tanaka and Chen, 2012), we monitored the interactions between STING and TBK1 by coimmunoprecipitation assay. We found that binding of STING and TBK1 has increased in CX lysate after TBI (Fig. 1E). However, binding between STING and TBK1 was inhibited by treatment with GSK2656157 following TBI (Fig. 1E). Together, these data suggest that ER stress activates the STING-signaling pathway, which subsequently activates IRF3 by increasing its phosphorylation following TBI.

In the nucleus, activated IRF3 is known to bind to the type I IFN promoter to synthesize IFN $\beta$, and other genes involved in innate immunity. To confirm that TBI induced neuronal ER stress is responsible for activation of innate immune response pathways, we performed qRT-PCR for IFN $\beta$ and IFN $\alpha$ with total RNA extracted from CX tissue with or without treatment with GSK2656157. Our data show that expression of IFN $\beta$ and IFN $\alpha$ were increased significantly in the CX of TBI mice compared with sham (Fig. $1 F$ ); however, expression remained near sham values with GSK2656157 treatment after TBI (Fig. $1 F$ ). Interestingly, we found that the increase in IFN $\beta$ expression was much higher than the increase in IFN $\alpha$ expression level. The increased expression of IFN $\beta$ in the mouse brain following TBI was further confirmed by ELISA assay for IFN $\beta$ and IFN $\alpha$ using pericontusional cortical tissue lysate and by immunofluorescence staining and confocal analysis of IFN $\beta$ along with NeuN in brain sections after TBI with or without $50 \mathrm{mg} / \mathrm{kg}$ GSK2656157 treatment. Similar to qRTPCR data the ELISA assay showed significantly increased expression of IFN $\beta$ and IFN $\alpha$ in the pericontusional cortex of TBI mice compared with sham (Fig. $1 G$ ); however, it was significantly abrogated by treatment with GSK2656157 after TBI (Fig. 1G). Our confocal analysis data show increased IFN $\beta$ expression in pericontusional cortical neurons of TBI mice compared with sham (Fig. $1 H$ and Fig. 1-1 I, J, available at https://doi.org/10.1523/JNEUROSCI.0718-19.2019.f1-1); however, it was significantly attenuated by treatment with GSK2656157 after TBI (Fig. 1 Hand Fig. 1-1 I, J, available at https://doi.org/10.1523/JNEUROSCI.0718-19.2019.f1-1). Together these findings indicate that neuronal ER stress mediates crosstalk between STING-TBK1-IRF3 pathways after TBI, which results in increased type I IFN production involved in innate immunity.

\section{Dose-dependent effect of GSK2656157 (10, 20, or $50 \mathrm{mg} / \mathrm{kg}$ body weight) on activation of STING signaling to synthesize IFN $\beta$}

Previously we have shown that administration of GSK2656157 inhibits PERK phosphorylation in a dose-dependent manner (Sen et al., 2017). To study the specific effect of PERK inhibition on the STING signaling and IFN $\beta$ production we tested the influence of GSK2656157 on IFN $\beta$ production by RT-PCR and ELISA in a dose-dependent manner $(10,20$, or $50 \mathrm{mg} / \mathrm{kg}$ body weight) in CX tissue. Under similar experimental conditions, we monitored the P-TBK1, P-IRF3, P-STING in CX tissue by WB analysis. Our qRT-PCR and ELISA data show that administration of GSK2656157 even at a lower dose (10 mg/kg body weight) significantly reduced TBI induced IFN $\beta$ expression after TBI (Fig. 1-1K,L, available at https://doi.org/10.1523/JNEUROSCI.0718-19. 2019.f1-1). Western blot analysis also confirmed that treatment of lower dose of GSK2656157 also abrogates the increased level of phospho-STING, phospho-TBK1 and phospho-IRF3 levels (Fig. $1-1 M, N$, available at https://doi.org/10.1523/JNEUROSCI.071819.2019.f1-1). These data further strengthen the findings that ER stress is critical to trigger STING-TBK1-IRF3 pathways to synthesize overproduction of type I IFN after TBI. 



Figure 1. TBI induces ER stress in neurons and activates STING signaling to synthesize IFN $\beta$. Mice were subjected to TBI with or without $50 \mathrm{mg} / \mathrm{kg}$ GSK2656157 for $3 \mathrm{~d}$, and the following experiment was performed. $A$, The confocal microscopic analysis in the pericontusional $C X$ shows that $3 \mathrm{~d}$ after TBI phosphorylated-PERK is increased and enriched mostly in neurons as indicated by colocalization of phospho-PERK and a neuronal marker, NeuN compared with sham. B, The confocal microscopic analysis of phospho-STING along with NeuN in CX shows that $3 \mathrm{~d}$ after TBI expression of phospho-STING is increased in the neurons compared with sham. Treatment of GSK2656157 after TBI decreased phospho-STING expression compared with untreated TBI. C, The confocal microscopic analysis of phospho-TBK1 along with NeuN in CX shows that $3 \mathrm{~d}$ after TBI expression of P-TBK1 is increased in the neurons compared with sham. Treatment of GSK2656157 after TBI decreased P-TBK1 level compared with untreated TBI. D, The confocal microscopic analysis of phospho-IRF3 along with NeuN in CX shows that $3 \mathrm{~d}$ after TBI expression of P-IRF3 is increased and localized in the neuronal nucleus compared with sham. Treatment of $50 \mathrm{mg} / \mathrm{kg}$ GSK2656157 for $3 \mathrm{~d}$ after TBI decreased P-IRF3 level and nuclear localization compared with untreated TBI. E, Co-IP assay to monitor the interaction between STING and TBK1 in CX lysate after TBI with or without GSK2656157. The representative figure (top) is shown along with the densitometry analysis (bottom). ${ }^{*} p<0.05, n=5$ ( 3 male and 2 female mice in each group), one-way ANOVA, mean \pm SEM. $\boldsymbol{F}$, Quantitative RT-PCR analysis for IFN $\beta$ and IFN $\alpha$ (normalized to actin) with total mRNA from pericontusional cortex tissue. G, ELISA assay was performed to measure the production of IFN $\beta$ and IFN $\alpha$ with the pericontusional cortex tissue lysate after treatment (Figure legend continues.) 
TBI-mediated activation of STING signaling, and IFN $\beta$ synthesize was blocked by siRNA-mediated knockdown of PERK in the mouse brain

To verify the specific effect of PERK inhibition on STING signaling and IFN $\beta$ production, we performed intranasal PERK knockdown by siRNA immediately after TBI. Consistent with results from GSK2656157 treatment, PERK knockdown decreased PERK phosphorylation and attenuated the increased level of phospho-STING, phospho-TBK1 and phospho-IRF3 levels (Fig. 2-1 A, B, available at https://doi.org/10.1523/JNEUROSCI.071819.2019.f2-1) in CX after TBI. Furthermore, the co-IP data showed that similar to treatment with GSK2656157, the interaction between STING and TBK1 was abrogated by PERK knockdown following TBI (Fig. 2-1C, available at https://doi.org/10.1523/ JNEUROSCI.0718-19.2019.f2-1). As expected, our qRT-PCR and ELISA data show significant reduction in TBI induced IFN $\beta$ expression in CX after PERK knockdown following TBI (Fig. 2-1 D, E, available at https://doi.org/10.1523/JNEUROSCI.0718-19.2019.f2-1). Together, these data further imply that ER stress or PERK mediates crosstalk between STING-TBK1-IRF3 pathways results in increased IFN $\beta$ production after TBI.

\section{IFN $\beta$ is induced in primary neuron culture after ER stress inducer, tunicamycin, in the presence or absence of GSK2656157}

To further show that neurons can evoke an innate immune response through ER stress-mediated activation of STING-TBK1IRF3 pathway, we treated primary cortical neuronal culture with an ER stress inducer, tunicamycin $(3 \mu \mathrm{g} / \mathrm{ml})$ with or without GSK2656157 $(15 \mu \mathrm{g} / \mathrm{ml})$ for $6 \mathrm{~h}$. After treatment with tunicamycin, we confirmed PERK activation in the primary neuron culture by WB analysis (Fig. 2A,B). Similar to in vivo TBI-mediated ER stress, ER stress induction in primary neuron show increased phospho-STING expression as well as an increased level of phospho-TBK1 and phospho-IRF3 compared with control (Fig. $2 A, B)$. However, treatment of GSK2656157 abrogated the increased level of phospho-STING as well as phospho-TBK1 and phospho-IRF3 levels (Fig. 2A,B). The coimmunoprecipitation data show that tunicamycin increased the interaction between STING and TBK1, and the interaction was attenuated by treatment with GSK2656157 (Fig. 2C,D). Total RNA extracted from tunicamycin treated neurons were subjected to qRT-PCR to confirm the expression of IFN $\beta$ with or without treatment with GSK2656157 and normalized to actin. Our data show significantly increased relative expression of IFN $\beta$, and a moderate increase in IFN $\alpha$ expression in tunicamycin-treated primary neuron culture compared with untreated control (Fig. 2E). The increase in IFN $\beta$ expression was significantly diminished by treatment with both GSK2656157 and tunicamycin compared with tunicamycin alone (Fig. $2 E$ ). The increased expression and release of IFN $\beta$ from tunicamycin-treated primary neuron culture was further confirmed by ELISA assay using the culture media (Fig. 2F) and confocal microscopic analysis in CX (Fig. $2 G, H)$. Together these findings confirmed that neuronal ER

\section{$\leftarrow$}

(Figure legend continued.) with or without GSK2656157. Data are expressed as fold increase in IFN $\alpha$ and IFN $\beta$ level over Sham levels. ${ }^{*} p<0.05, n=5$ ( 3 male and 2 female mice in each group), one-way ANOVA, mean \pm SEM. $\boldsymbol{H}$, The confocal microscopic analysis of IFN $\beta$ along with NeuN in Cortex (CX) shows that $3 \mathrm{~d}$ after TBI expression of IFN $\beta$ is increased in the neurons compared with sham. Treatment of $50 \mathrm{mg} / \mathrm{kg}$ GSK2656157 for $3 \mathrm{~d}$ after TBI decreased IFN $\beta$ expression compared with untreated TBI. (Figure 1-1, available at https:// doi.org/10.1523/JNEUROSCI.0718-19.2019.f1-1). stress mediates crosstalk between the STING-TBK1-IRF3 pathway after TBI, which results in increased type I IFN production (especially IFN $\beta$ ) involved in innate immunity. Then we were interested to elucidate the mechanism of how IFN $\beta$ may affect innate immune response following TBI.

\section{TBI induced microglia activation and polarization to M1 phenotype was attenuated by GSK 2656157}

As the primary mediators of the innate immune response in the CNS, microglia play a critical role in neuroinflammation and secondary injury after TBI. The dual beneficial and detrimental roles for microglia results in tissue repair or neurodegeneration, respectively. Previous experimental and clinical studies demonstrate a chronic and persistent M1-like phenotype of microglia predominates over M2-like phenotype of microglia after TBI (Loane and Kumar, 2016). We tested whether an inhibitor of neuronal ER stress by treatment with GSK2656157 or intranasal PERK knockdown by siRNA may have any effect on microglia activation and polarization after TBI. For that purpose, we examined microglia/macrophage activation and polarization by coimmunofluorescent staining of the M1 marker CD16/32, or M2 marker CD206 with a microglial/macrophage marker, ionized calcium-binding adapter molecule 1 (Iba-1) in brain sections after TBI with or without treatment with $50 \mathrm{mg} / \mathrm{kg}$ GSK2656157 or intranasal PERK knockdown by siRNA immediately after TBI. Iba-1 staining demonstrated robust activation of microglia/macrophages in the $\mathrm{CX}$ at $3 \mathrm{~d}$ post-injury compared with shaminjured controls (Fig. $3 A$ and Fig. 3-1A, C, available at https:// doi.org/10.1523/JNEUROSCI.0718-19.2019.f3-1). Microglia/ macrophages in sham-injured controls had small cell bodies with thin, long, and highly branched processes indicative of a surveilling status. However, following TBI, microglia transformed to a highly activated state, their branched processes were withdrawn to form thick bundles around highly enlarged cell bodies, and their number was significantly increased at the site of injury (Fig. $3 A$ and Fig. 3-1 $A, C$, available at https://doi.org/ 10.1523/JNEUROSCI.0718-19.2019.f3-1). Furthermore, immunofluorescence imaging revealed that there was increased protein expression of Iba- 1 in highly activated microglia/macrophages at $3 \mathrm{~d}$ post-injury (Fig. $3 A$ and Fig. 3-1A, available at https:// doi.org/10.1523/JNEUROSCI.0718-19.2019.f3-1). The assessment of microglial/macrophage polarization dynamics using CD16/32 and CD206 antibody with Iba-1 showed most of CD16/32 marker colocalized with Iba-1 3 d post-TBI, and its expression exhibited changes similar to those observed for Iba-1, which indicated that the M1 phenotype of microglia/macrophages increased in the pericontusional cortex following TBI compared with sham-injured mice (Fig. $3 A, B$, and Fig. 3-1 $B$, available at https://doi.org/10.1523/JNEUROSCI.0718-19.2019.f3-1). CD206 staining changed little in the pericontusional cortex of TBI-mice compared with sham-injury mice (Fig. $3 B$ and Fig. 3-1B, available at https://doi.org/10.1523/JNEUROSCI.071819.2019.f3-1), suggesting that TBI increased microglial/macrophage polarization to mostly M1 phenotype. However, $3 \mathrm{~d}$ of treatment with GSK2656157 moderately decreased the expression level of Iba-1 (Fig. 3A and Fig. 3-1A, available at https:// doi.org/10.1523/JNEUROSCI.0718-19.2019.f3-1). Moreover, CD16/32 expression and colocalization with Iba-1 decreased concomitantly with increased CD206 expression and coexpression with Iba-1 (Fig. 3A, B, and Fig. 3-1B, available at https:// doi.org/10.1523/JNEUROSCI.0718-19.2019.f3-1). Similar to the GSK2656157 treatment, the intranasal administration of PERK siRNA after TBI decreased CD16/32 expression and colocaliza- 

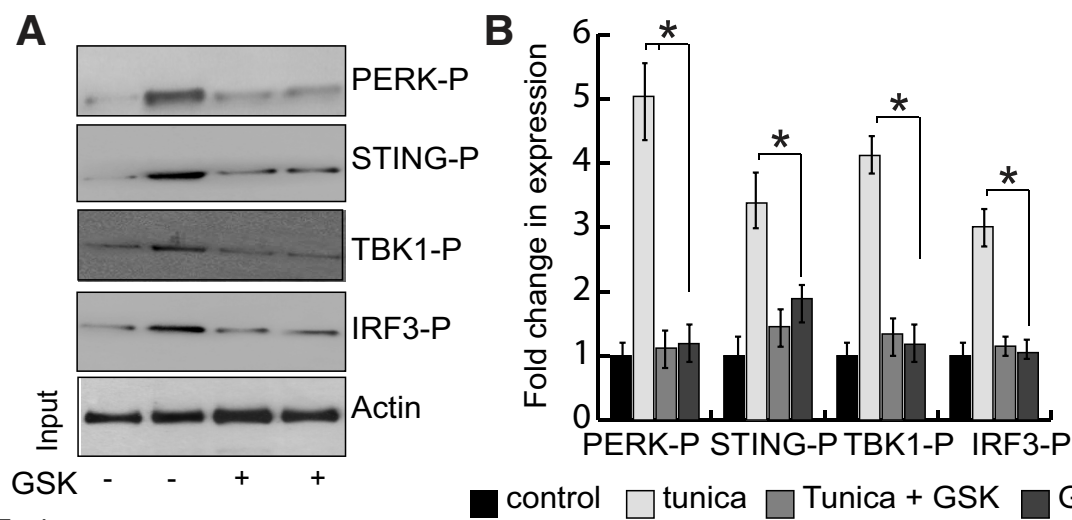

control $\square$ tunica $\square^{\text {Tunica }+ \text { GSK } \square \text { GSK }}$

Tunica - + + -

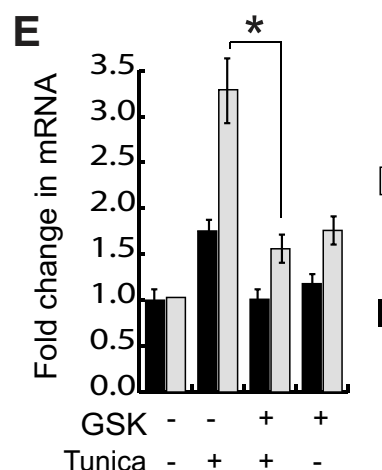

RT-PCR

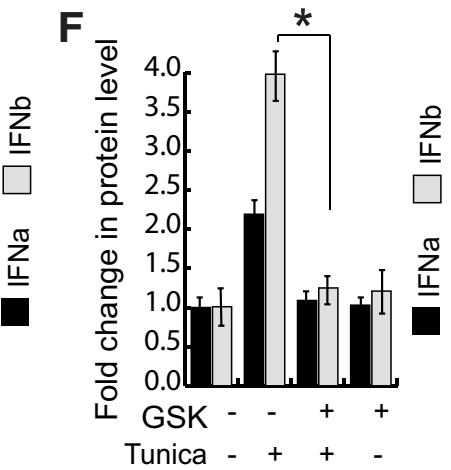

ELISA
C IP:

STING

플

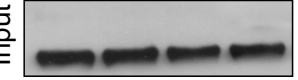

TBK1

$\begin{array}{rrrrr}\text { GSK } & - & - & + & + \\ \text { Tunica } & - & + & + & -\end{array}$

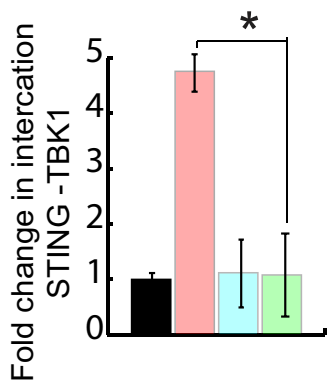

control $\square$ tunica $\square$ Tunica + GSK

GSK
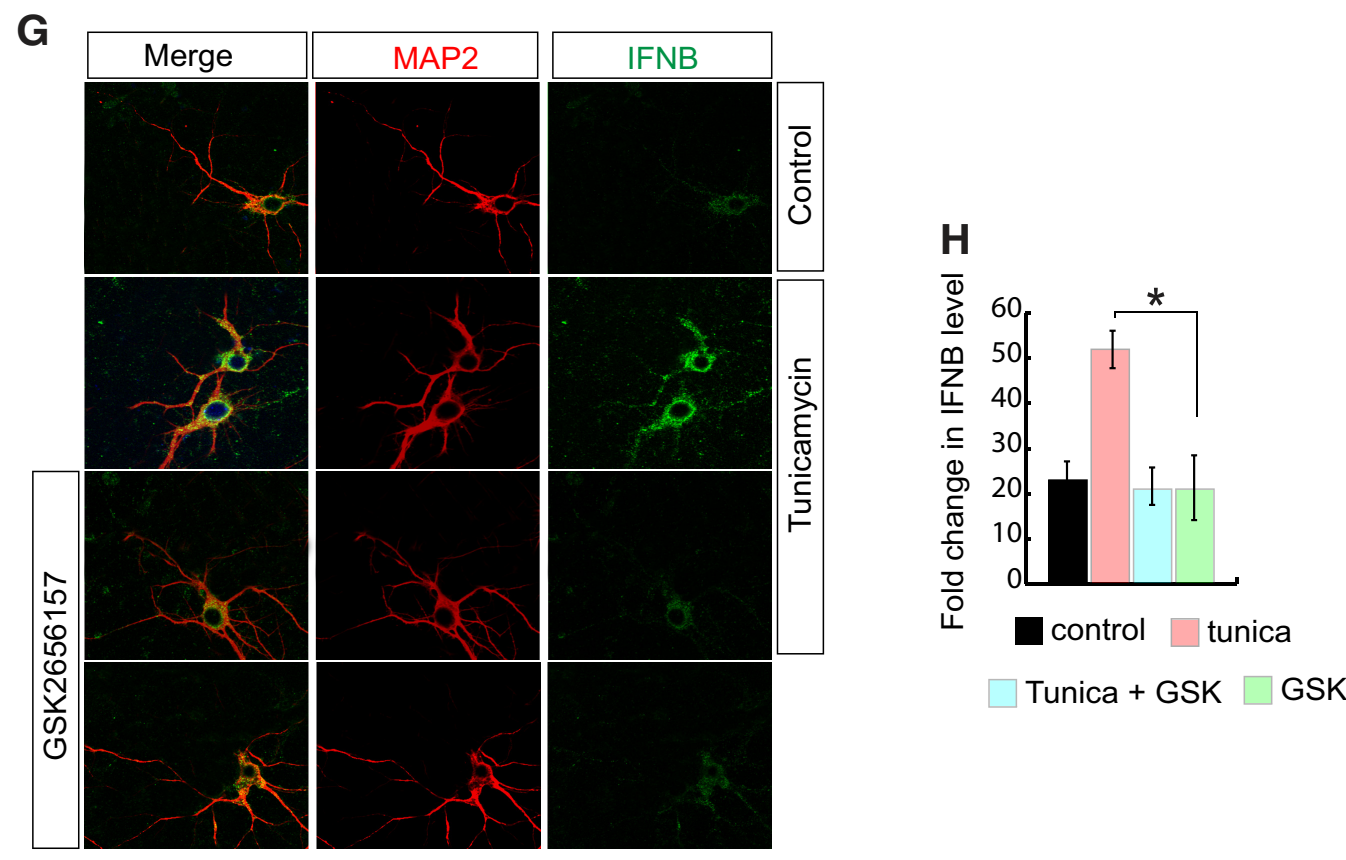

Figure 2. ER stress inducer, tunicamycin, increased interferon (IFN) $\beta$ production in primary neuronal culture. The primary neuronal culture was treated with tunicamycin ( $3 \mu \mathrm{g} / \mathrm{ml})$ with or without GSK2656157 (15 $\mu \mathrm{g} / \mathrm{ml})$ treatment for $6 \mathrm{~h}$, and the following experiment was performed. $\boldsymbol{A}, \boldsymbol{B}$, WB analysis of phospho-PERK, phospho-TBK1, phospho-IRF3, and phospho-STING expression in the primary cortical neuronal lysate. Actin is considered as a loading control. The representative figure $(\boldsymbol{A})$ is shown along with the densitometric analysis $(\boldsymbol{B}) .{ }^{*} p<0.05, n=5(3$ male and 2 female mice in each group), one-way ANOVA, mean \pm SEM. C, D, Co-IP assay to monitor the interaction between either STING and TBK1 in the primary cortical neuronal lysate. The representative figure $(\boldsymbol{C})$ is shown along with the densitometric analysis (D). ${ }^{*} p<0.05, n=5$ ( 3 male and 2 female mice in each group), one-way ANOVA, mean \pm SEM. $E$, Quantitative RT-PCR analysis for ifn $\beta$ and ifn $\alpha$ (normalized to actin) with total mRNA from the primary cortical neuron. ${ }^{*} p<0.05, n=5$, one-way ANOVA, mean \pm SEM. $F$, ELISA assay was performed to measure the production of IFN $\beta$ and IFN $\alpha$ in the primary cortical neuronal culture supernatant after tunicamycin treatment with or without GSK2656157. Data are expressed as fold increase in IFN $\alpha$ and $\beta$ level over control levels. ${ }^{*} p<0.05, n=5$ (3 male and 2 female mice in each group), one-way ANOVA, mean \pm SEM. $\boldsymbol{G}, \boldsymbol{H}$, The confocal microscopic analysis of IFN $\beta$ along with MAP2 in primary cortical neuronal culture with tunicamycin with or without GSK2656157 treatment shows increased IFN $\beta$ production in tunicamycin-treated cells compared with control. Treatment of GSK2656157 with tunicamycin decreased IFN $\beta$ expression compared with tunicamycin treatment alone. Representative figure $(\boldsymbol{G})$ is on the left, and the quantification on the right $(\boldsymbol{H})$ shows binary analysis of the area of IFN $\beta$-expressing primary neurons by ImageJ analysis software; ${ }^{*} p<0.05, n=5$ (3 male and 2 female mice in each group), one-way ANOVA, mean \pm SEM (Figure 2-1, available at https://doi.org/10.1523/JNEUROS(I.0718-19.2019.f2-1). 

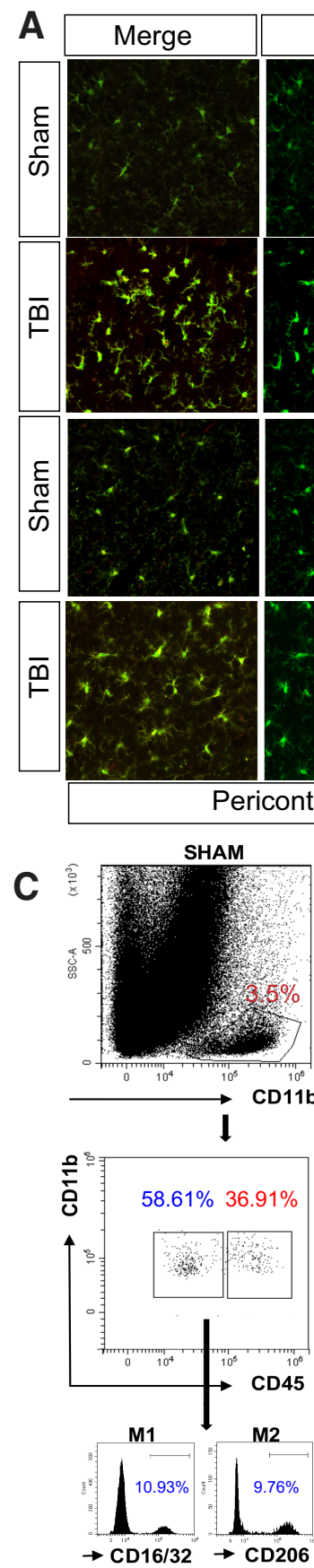

$\rightarrow \mathrm{CD} 16 / 32 \rightarrow \mathrm{CD} 206$

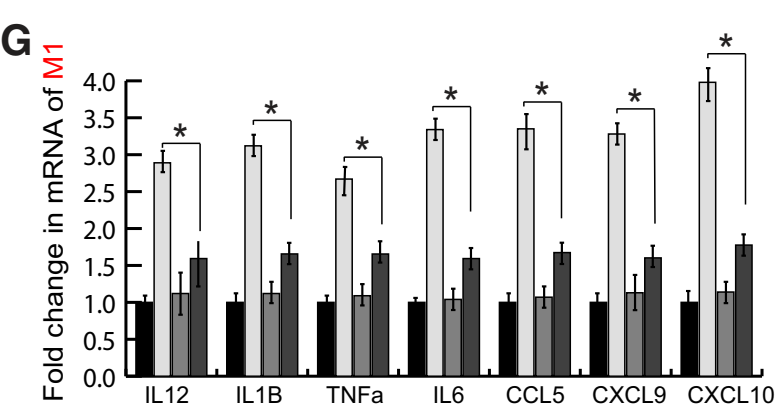

B

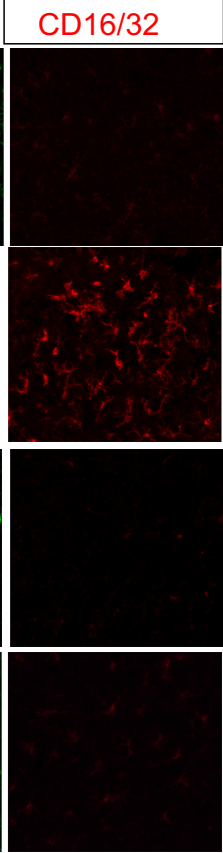

TBI
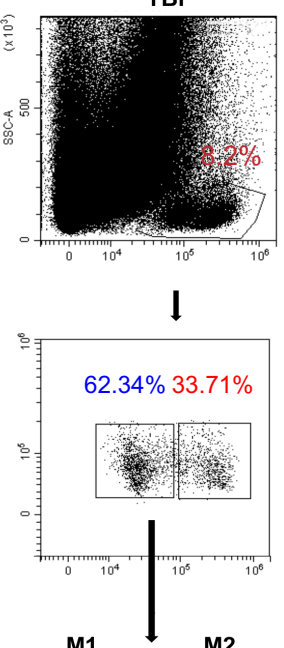

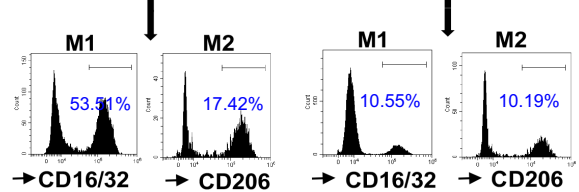

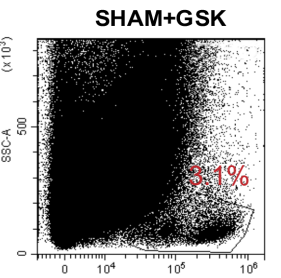

I

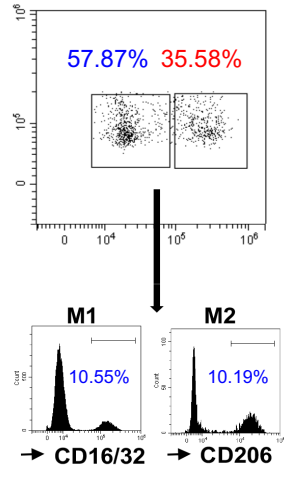

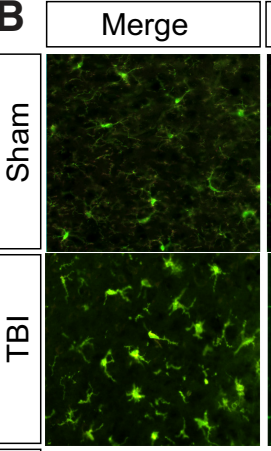
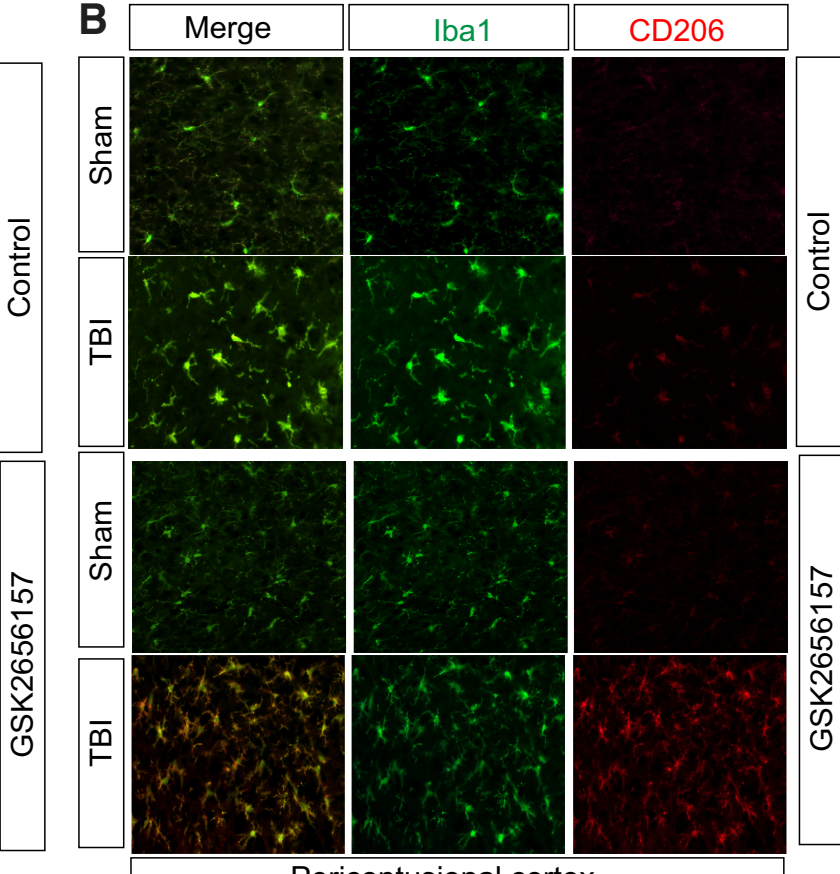

Pericontusional cortex

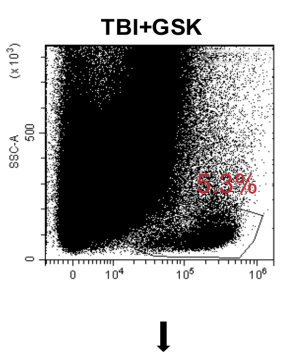

D

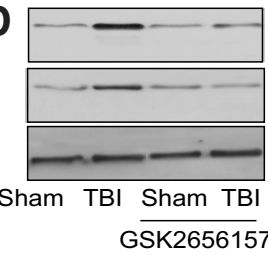

E
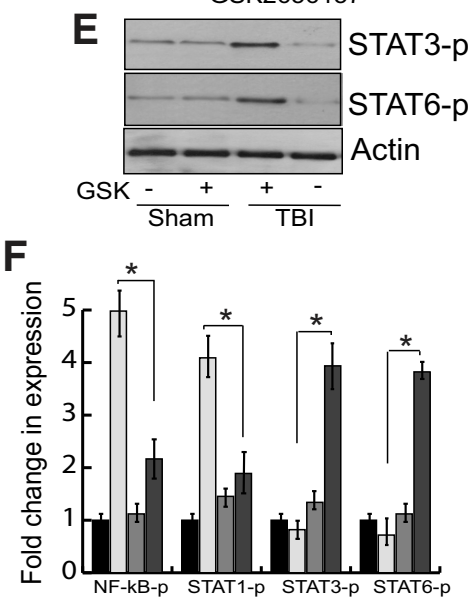

$\square$ Sham $\square \mathrm{TBI} \square$ Sham+GSK $\square$ TBI+GSK

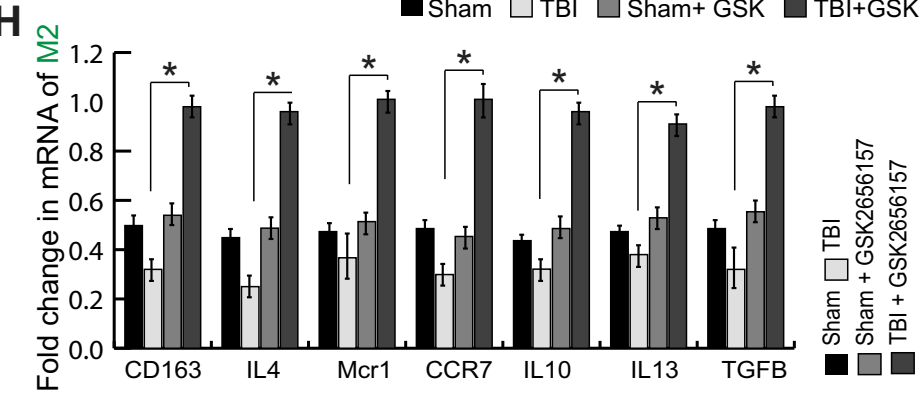

Figure 3. TBI induced microglia activation and M1 polarization were attenuated by GSK2656157. Mice were subjected to TBI with or without $50 \mathrm{mg} / \mathrm{kg}$ GSK2656157 for $3 \mathrm{~d}$, and the following experiment was performed. $\boldsymbol{A}$, The confocal microscopic analysis shows that $3 \mathrm{~d}$ after TBI Iba- 1 and CD16/32 expression is increased in the pericontusional cortex compared with sham. Treatment of GSK2656157 after TBI significantly decreased CD16/32 expression compared with untreated TBI. B, The confocal microscopic analysis of lba- 1 and CD206 shows that CD206 expression is increased in GSK2656157-treated TBI pericontusional cortex compared with TBI. C, Microglia/macrophage cells were selected using CD11b (boxes, top) and analyzed using CD45 to differentiate infiltrating macrophages (CD11b ${ }^{+} \mathrm{CD} 45^{\text {high }}$; middle row, right box) from resident microglia (CD11b ${ }^{+}$CD45 ${ }^{\text {low; }}$; middle row, left box). The polarization of microglia was (Figure legend continues.) 
tion with Iba-1 and correspondingly increased CD206 expression and coexpression with Iba-1 (Fig. 3 Fig. 3-1D-G, available at https://doi.org/10.1523/JNEUROSCI.0718-19.2019.f3-1). These data suggest that preventing ER stress shifts the population of microglial cells to the direction of the M2 phenotype.

To further confirm the influence of ER stress on microglial/ macrophage activation, the cells from the pericontusional cortex at $3 \mathrm{~d}$ post-injury with or without $50 \mathrm{mg} / \mathrm{kg}$ GSK2656157 treatment was assessed by flow cytometry analysis. Cells were labeled with CD11b and CD45 antibodies to differentiate peripheral myeloid cells (macrophages; CD $11 b^{+} / \mathrm{CD} 45^{\text {high }}$ ) from resident microglia $\left(\mathrm{CD} 11 \mathrm{~b}^{+} / \mathrm{CD} 45^{\text {low }}\right.$ ) based on CD45 expression (Stirling and Yong, 2008). Compared with sham-injured mice the levels of $\mathrm{CD}_{1} \mathrm{~b}^{+}$populations were significantly increased in mice $3 \mathrm{~d}$ postTBI (Fig. 3C, top). Gating on CD $45^{\text {high }}$ populations revealed a robust infiltration of peripheral macrophages into the CCI brain compared with sham-injured levels (Fig. $3 C$, middle). We performed flow cytometry analysis for selected M1- and M2-like polarization using CD86 and CD208 antibodies and found that there was a significant increase in $\mathrm{M} 1$ microglia $\left(\mathrm{CD} 11 \mathrm{~b}^{+} \mathrm{CD} 86^{+}\right)$population, at $3 \mathrm{~d}$ post-injury versus sham. Also, markers of M2-like microglia polarization $\left(\mathrm{CD} 11 \mathrm{~b}{ }^{+} \mathrm{CD} 206^{+}\right)$was slightly changed in TBI versus sham (Fig. $3 C$, bottom), confirming that TBI induced microglial polarization mostly to the M1 phenotype. Interestingly, 3-d of treatment with GSK2656157 significantly decreased the infiltration of peripheral macrophages into the TBI brain compared with TBI only brain (Fig. 3C, middle). Concomitantly, GSK2656157 treatment significantly increased the $\mathrm{M} 2$ microglia $\left(\mathrm{CD} 11 \mathrm{~b}{ }^{+} \mathrm{CD} 206^{+}\right.$) population in the mouse brain following TBI. In addition, markers of M1-like microglia polarization $\left(\mathrm{CD} 11 \mathrm{~b}^{+} \mathrm{CD} 86^{+}\right)$were significantly decreased in GSK2656157 treated TBI brain versus TBI brain (Fig. 3C, bottom), confirming that inhibition of ER stress can shift M1 microglia to the M2 phenotype. Then we were interested to elucidate the mechanism of how prevention of ER stress mitigates the activation of M1-like microglial cells following TBI.

Activation of STAT1 signaling pathways by IFNs signaling and NF- $\kappa \mathrm{B}$ are known to skew microglia/macrophage function toward the M1 phenotype, while activation of STAT6 signaling pathways by IL-4 and IL-13 and the STAT3 pathway by IL-10 can skew microglia/macrophage function toward the M2 phenotype (Sica and Mantovani, 2012). Previous reports have shown that type I interferons can bind to the type I IFNAR with consequent activation of the transcription factor STAT1 in microglia/macrophages (N. Wang et al., 2014). IFN-stimulated genes include chemokine CXCL9 and CXCL10 (Donlin et al., 2014), which are again characteristic of classical M1 microglia/macrophage activation. Therefore, to understand whether ER stress-mediated neuronal IFNs may regulate microglial/macrophage polarization dynamics, we performed WB analysis with CX tissue lysate to test

$\leftarrow$

(Figure legend continued.) assessed using M1 marker CD86 or M2 marker CD206 (bottom row, histogram). Representative Scatterplots and histogram are provided of five independent experiments using three male and two female mice in each group. $\boldsymbol{D}-\boldsymbol{F}$, WB analysis of NF- $\kappa B$, STAT1, STAT3, and STAT6 phosphorylation in CX lysate show that, whereas NF- $\kappa$ B and STAT1 phosphorylation is decreased the STAT3, and STAT6 phosphorylation is increased in GSK2656157treated TBI pericontusional cortex compared with TBI. The representative figures $(\boldsymbol{D}, \boldsymbol{E})$ are shown along with the densitometric analysis $(\boldsymbol{F}) .{ }^{*} p<0.05, n=5$ ( 3 male and 2 female mice in each group), one-way ANOVA, mean \pm SEM. $\mathbf{G}, \boldsymbol{H}$, Quantitative RT-PCR analysis for M1markers il-12, il-1 $\beta$, tnf $\alpha$, il-6, ccl5, cxcl9, and $\mathrm{cxcl10}$ (G); and M2-markers CD163, IL4, mcr1, $\mathrm{ccr} 7$, ill10, il13, and $\operatorname{tgf} \beta$ ( $\boldsymbol{H}$; normalized to actin) with total mRNA from pericontusional cortex tissue. ${ }^{*} p<0.05, n=5$ ( 3 male and 2 female mice in each group), one-way ANOVA, mean \pm SEM (Figure 3-1, available at https://doi.org/10.1523/JNEUROSCI.0718-19.2019.f3-1). activation of NF- $\kappa \mathrm{B}$, STAT1, STAT3, and STAT 6 with or without GSK2656157 treatment. Our study shows an increased level of phospho-NF- $\kappa$ B and phospho-STAT1 and decreased phosphoSTAT3 and phospho-STAT6 in the TBI-injured CX tissue lysate compared with sham (Fig. $3 D-F$ ). However, $3 \mathrm{~d}$ of $50 \mathrm{mg} / \mathrm{kg}$ GSK2656157 treatment after TBI significantly decreased phospho$\mathrm{NF}-\kappa \mathrm{B}$ and phospho-STAT1 levels and concurrently increased phospho-STAT3 and phospho-STAT6 levels in the TBI-injured pericontusional CX (Fig. 3D-F). To further assess microglial/ macrophage polarization dynamics, we collected perilesional cortical tissue from mice at $3 \mathrm{~d}$ post-TBI for gene expression analysis of markers of M1- and M2-like polarized microglia/macrophages. M1-like markers included IL-1 $\beta$, TNF $\alpha$, IL-6, IL-12, CCL5, CXCL9, and CXCL10 mRNAs, and M2-like markers included CD163, IL4, Mcr1, CCR7, IL10, IL13, and TGF $\beta$ mRNAs. Compared with sham-injured control levels, there was a robust induction of M1-like genes and reduction in M2-like genes following 3 d TBI (Fig. 3G,H). However, 50 mg/kg GSK2656157 treatment or intranasal PERK knockdown by siRNA significant decreased M1-like gene expression and increased M2-like gene expression after TBI versus untreated mice (Fig. $3 G, H$, and Fig. 3-1 H,I, available at https://doi.org/10.1523/JNEUROSCI.071819.2019.f3-1), confirming that ER stress mediated neuronal IFNs especially IFN $\beta$ plays a key role in microglia/macrophage polarization dynamics following TBI.

\section{IFN $\beta$ induces microglial activation and polarization to M1 phenotype in primary microglia culture}

To gain further insight into the IFN $\beta$ mediated microglial activation and polarization, we treated primary microglia culture with IFN $\beta(100 \mathrm{U} / \mathrm{ml})$ with or without GSK2656157 $(15 \mu \mathrm{g} / \mathrm{ml})$ for $24 \mathrm{~h}$ at $37^{\circ} \mathrm{C}$. In general, ramified quiescent microglia changes to an activated state displaying larger somata and shorter, coarser cytoplasmic processes progressing to a full amoeboid morphology (Harry, 2013). Interestingly, Iba-1 immunostaining data show that IFN $\beta$ treatment activated microglia culture with a propensity to acquire a more ramified morphology with thicker and more extensive processes (Fig. $4 A$ and Fig. $4-1 A$, available at https://doi.org/10.1523/JNEUROSCI.0718-19.2019.f4-1). Coimmunostaining with CD16/32 or CD206 shows that although CD206 staining was not much different from control (Fig. $4 B$ and Fig. 4-1B, available at https://doi.org/10.1523/JNEUROSCI.071819.2019.f4-1), most of these activated microglia have increased CD16/32 staining compared with the untreated control cells (Fig. $4 A$ and Fig. 4-1 $A$, available at https://doi.org/10.1523/ JNEUROSCI.0718-19.2019.f4-1), indicating M1 polarization. Interestingly, adding GSK2656157 did not have any effect on IFN $\beta$ mediated microglial activation and polarization compared with IFN $\beta$ treatment alone (Fig. $4 A$ and Fig. 4-1 $A$, available at https://doi.org/10.1523/JNEUROSCI.0718-19.2019.f4-1). Furthermore, induction of ER stress by tunicamycin could not do any effect on microglia activation and phenotypic changes compared with untreated cells (Fig. 4A and Fig. 4-1 $A$, available at https://doi.org/ 10.1523/JNEUROSCI.0718-19.2019.f4-1), suggesting that ER stress and PERK activation in microglia has no direct effect on microglia activation and polarization.

The M1 phenotype after IFN $\beta$ treatment was further confirmed when we found increased phospho-NF- $\kappa \mathrm{B}$ and phospho-STAT1 staining in IFN $\beta$ treated microglia compared with that of untreated control (Fig. $4 C, D$, and Fig. 4-1C,D, available at https://doi.org/ 10.1523/JNEUROSCI.0718-19.2019.f4-1). To further assess microglial polarization dynamics by IFN $\beta$, we analyzed the mRNA expression of markers of M1- (IL-1 $\beta$, TNF $\alpha$, IL-6, CCL5, CXCL9, 

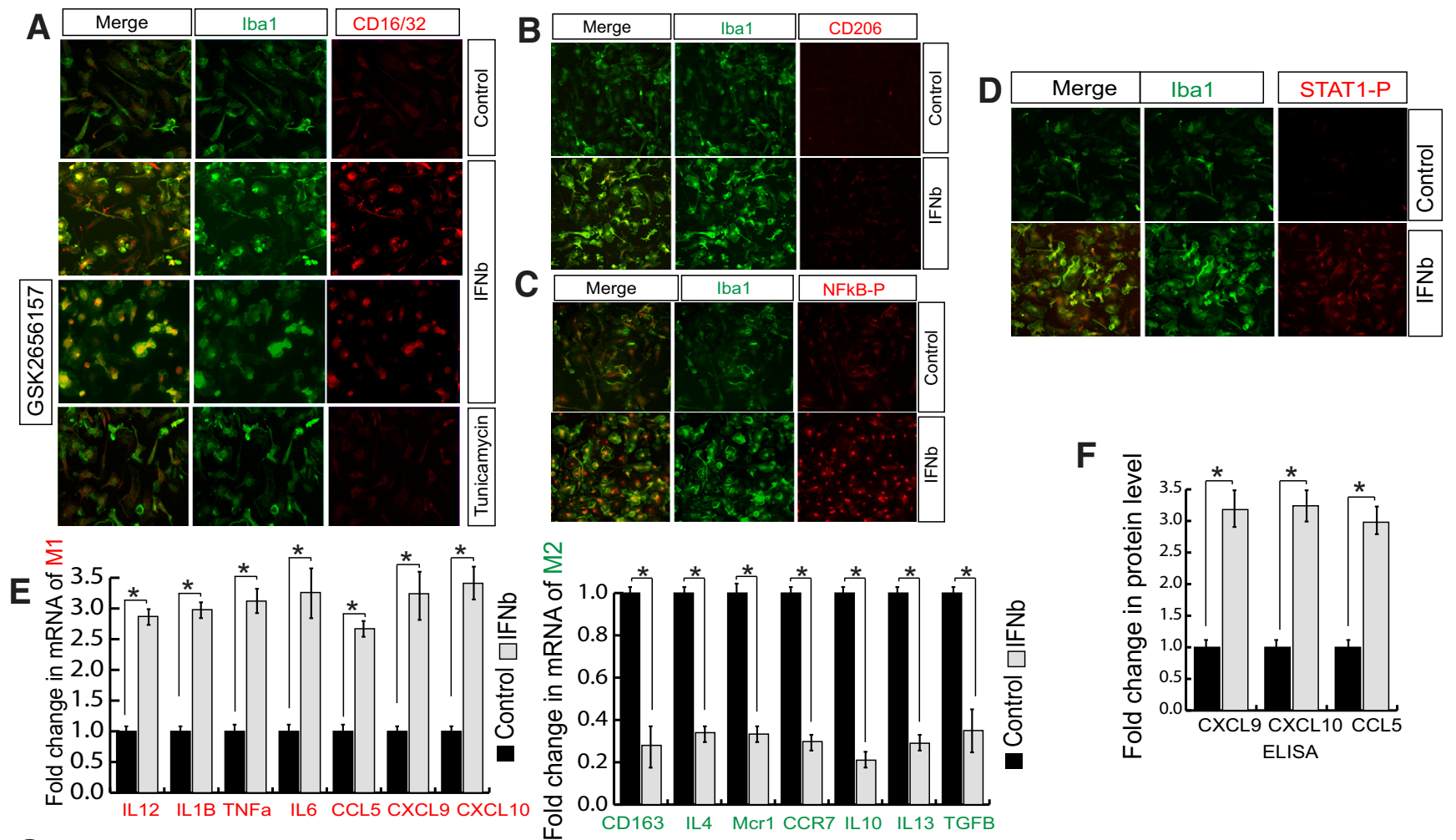

G

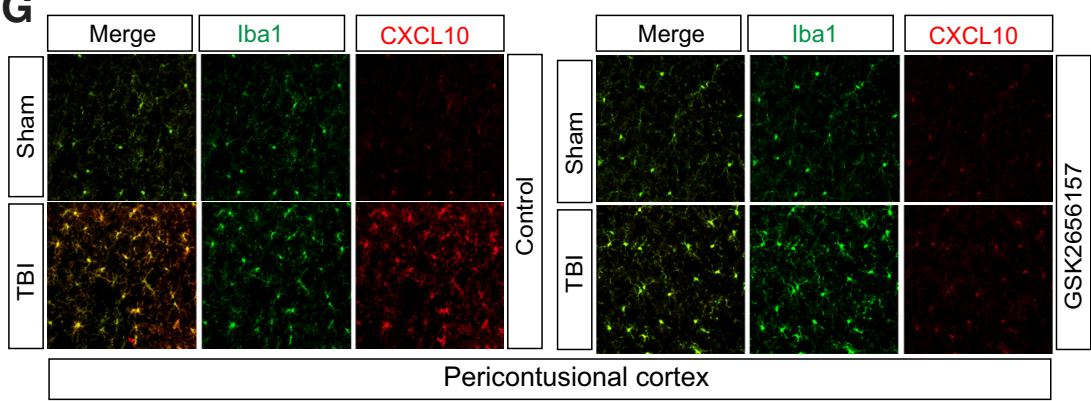

H
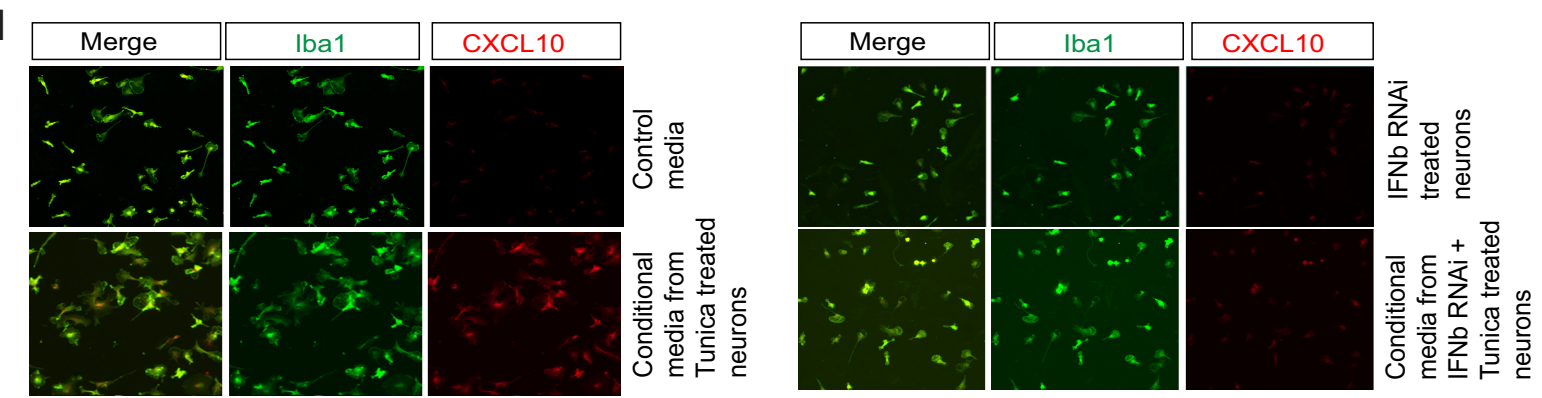

Figure 4. IFN $\beta$ induces primary microglia activation and polarization to M1 phenotype. The primary microglia culture was treated with IFN $\beta(100 \mathrm{U} / \mathrm{ml})$ for $24 \mathrm{~h}$ at $37^{\circ} \mathrm{C}$ with or without GSK2656157 (15 $\mu \mathrm{g} / \mathrm{ml})$ or tunicamycin $(3 \mu \mathrm{g} / \mathrm{ml})$ treatment and the following experiment was performed. $A$, The confocal microscopic analysis for lba- 1 and CD16/32 shows increased lba- 1 and CD16/32 expression in IFN $\beta$-treated cells compared with untreated cells. $\boldsymbol{B}$, The confocal microscopic analysis of Iba- 1 and CD206 shows that CD206 expression is not much changed after IFN $\beta$ treatment. $C$, The confocal microscopic analysis for Iba- 1 and phosphor-NF- $\kappa$ B shows increased NF- $\kappa$ B phosphorylation and nuclear localization in IFN $\beta$-treated cells compared with untreated cells. D, The confocal microscopic analysis for Iba-1 and phosphor-STAT1 shows increased STAT1 phosphorylation in IFN $\beta$-treated cells compared with untreated cells. E, Quantitative RT-PCR analysis for M1-markers IL-12, IL-1 $\beta$, TNF $\alpha$, IL-6, CCL5, CXCL9, and CXCL10 (top); and M2-markers CD163, IL4, Mcr1, CCR7, IL10, IL13, and TGF $\beta$ (bottom; normalized to actin) with total mRNA from IFN $\beta$-treated and untreated cell. ${ }^{*} p<0.05, n=5$, one-way ANOVA, mean \pm SEM. F, ELISA assay was performed to measure the production of CXCL10, CXCL9, and CCL5 in primary microglia culture after $24 \mathrm{~h}$ of IFN $\beta$ treatment. Data are expressed as fold increase in chemokine level over control levels. ${ }^{*} p<0.05, n=5$ ( 3 male and 2 female mice in each group), one-way ANOVA, mean \pm SEM. G, Mice were subjected to TBI with or without $50 \mathrm{mg} / \mathrm{kg} \mathrm{GSK2656157} \mathrm{for} 3 \mathrm{~d}$, and the confocal microscopic analysis for Iba- 1 and CXCL10 is performed in the tissue sections. $\boldsymbol{H}$, The confocal microscopic analysis for Iba- 1 and CXCL10 in cells treated with IFN $\beta$ shows increased expression of CXCL10 in activated microglia. $I$, The confocal microscopic analysis for Iba- 1 and CXCL10 in cells treated with or without IFN $\beta$ siRNA transfected and/or $6 \mathrm{~h}$ tunicamycin treated ( $3 \mu \mathrm{g} / \mathrm{ml}$ ) neuronal cultural media for $24 \mathrm{~h}$. (Figure 4-1, available at https://doi.org/ 10.1523/JNEUROSCI.0718-19.2019.f4-1. 
and CXCL10) and M2- (CD163, IL4, Mcr1, CCR7, IL10, IL13, and TGF $\beta$ ) like microglia. We found that mRNA expression of M1-like genes were significantly higher in IFN $\beta$ treated cells compared with untreated control (Fig. 4E). However, M2 markers were moderately decreased in IFN $\beta$-treated cells compared with untreated control (Fig. 4E). Collectively our data show that microglial ER stress has no direct influence on the activation of microglia/macrophages; however, the release of IFN $\beta$ from neurons upon induction of ER stress is critical for an increase in M1 phenotype of microglia/macrophages following TBI.

To further confirm the direct influence of IFN $\beta$ on microglial cells, we monitored the levels of three well characterized interferon-stimulated genes (ISG) chemokines, CXCL10, CXCL9, and CCL5 by ELISA after treating primary microglial cells with IFN $\beta$. Our data show that IFN $\beta$ induced a significantly high release for CXCL10 in IFN $\beta$-treated cells compared with untreated control culture media (Fig. 4F). Compared with CXCL10 the increase in CXCL9 and CCL5 levels were only moderately increased compared with the untreated media (Fig. $4 F$ ). The increased expression of CXCL10 was also confirmed in CX costained with Iba-1 compared with that of sham (Fig. $4 G$ and Fig. 4-1E, available at https://doi.org/10.1523/JNEUROSCI. 0718-19.2019.f4-1). Interestingly, treatment with $50 \mathrm{mg} / \mathrm{kg}$ GSK2656157 after TBI significantly decreased the expression of CXCL10 and its colocalization with Iba- 1 compared with only TBI (Fig. $4 G$ and Fig. 4-1E, available at https://doi.org/ 10.1523/JNEUROSCI.0718-19.2019.f4-1). The effect of ER stress on CXCL10 expression, PERK was depleted by intranasal PERK knockdown by siRNA after TBI, and it was shown that CXCL10 expression and colocalization with Iba-1 staining were decreased significantly (Fig. 4-1F, G, available at https://doi.org/ 10.1523/JNEUROSCI.0718-19.2019.f4-1); suggesting the connection between neuronal ER stress-dependent activation of IFN $\beta$ is directly responsible for microglial activation and CXCL10 production following TBI. Interestingly, microglia treated with IFN $\beta$ also show increased CXCL10 expression compared with untreated control by confocal microscopy (Fig. $4 H$ and Fig. 4-1H, available at https://doi.org/10.1523/JNEUROSCI.071819.2019.f4-1).

In another set of experiments, we used the conditioned-media from primary neurons treated with or without tunicamycin in the presence or absence of IFN $\beta$-knockdown (siRNA mediated). The primary microglia culture was incubated with the previouslymentioned conditioned neuronal media for $24 \mathrm{~h}$. Interestingly, microglia treated with conditioned media obtained from tunicamycintreated neuronal culture media showed ramified morphology of microglia with increased Iba-1 and CXCL10 expression compared with untreated microglia (Fig. $4 I$ and Fig. 4-1I, available at https:// doi.org/10.1523/JNEUROSCI.0718-19.2019.f4-1). However, microglia treated with conditioned media obtained from IFN $\beta$ siRNA and tunicamycin-treated neuronal culture showed no microglia activation and did not show significant changes in Iba-1 and CXCL10 expression compared with control microglia (Fig. 4I and Fig. 4-1 I, available at https://doi.org/10.1523/JNEUROSCI.0718-19.2019.f4$1)$. Together, our data suggest that, neuronal IFN $\beta$ can induce microglia activation and polarization to the M1 phenotype, and increase in type I ISG chemokines especially CXCL10 expression in microglia following TBI.

TBI induced Th1 infiltration was decreased with GSK2656157 or PERK siRNA treatment

Activated microglia can recruit peripheral blood-derived immune cells including $\mathrm{T}$ lymphocytes to infiltrate in the injured area and exaggerate the inflammation process (Olah et al., 2012; Zhao et al., 2015; Schafer et al., 2016). The recruitment of this activated T cells, especially CD4 T cells in the brain parenchyma after injury might be responsible for keeping up a long-term microglial activation that is found in human TBI brain samples. Thus, we monitored the status of $\mathrm{CD} 4{ }^{+} \mathrm{T}$-cell infiltration at the site of injury after TBI. Our FACS data show increased CD3 ${ }^{+}$ $\mathrm{T}$-cell infiltration at the site of injury $3 \mathrm{~d}$ after TBI compared with that of Sham (Fig. 5A, CD $45^{+}$column). However, the increase in $\mathrm{T}$-cell infiltration was significantly decreased after treatment with GSK2656157 (Fig. 5A, CD45 ${ }^{+}$column), suggesting that the increased T-cell infiltration is dependent on increased neuronal ER stress following TBI. We also found a significant increase in Th1 $\left(\mathrm{CD} 4{ }^{+} \mathrm{Tbet}^{+}\right) \mathrm{CD}^{+}{ }^{+} \mathrm{T}$-cell infiltration $3 \mathrm{~d}$ after TBI compared with that of sham (Fig. 5A). However, the number of Th2 $\left(\mathrm{CD} 4{ }^{+} \mathrm{GATA}^{+}\right)$and Treg $\left(\mathrm{CD} 4{ }^{+} \mathrm{FoxP}^{+}\right) \mathrm{CD}^{+}{ }^{+} \mathrm{T}$ cells were decreased $3 \mathrm{~d}$ after TBI compared with that of sham (Fig. 5A). Furthermore, the increase in Th1 cell infiltration was significantly reduced after treatment with GSK2656157, with a concomitant increase in the number of Th2 and Treg cells (Fig. 5A). Coimmunofluorescence staining with $\mathrm{CD} 4$ and CXCR3 (CD183) show increased $\mathrm{CD}^{+}{ }^{+} \mathrm{CXCR}^{+}{ }^{+}$(Th1) cell infiltration at TBI injury site compared with that of sham control. The $50 \mathrm{mg} / \mathrm{kg}$ GSK2656157 treatment rescued Th1 infiltration after TBI (Fig. 5B-D), suggesting that the ER stress-mediated increase in neuronal type I IFN innate immune response is associated with Th1-cell infiltration following TBI. These data were further confirmed when we found that similar to GSK2656157 treatment, intranasal administration of PERK siRNA significantly reduced CD4 and CXCR3-positive Th1 infiltration after TBI (Fig. 5-1A-C, available at https:// doi.org/10.1523/JNEUROSCI.0718-19.2019.f5-1).

\section{$\mathrm{T}$-cell infiltration and microglia activation are attenuated by knocking down CXCL10 after TBI}

The chemokine CXCL10 binds to the chemokine receptor CXCR3 on activated Th1 cells. The chemokine receptor CXCR3 plays an important role in chemo-attracting CXCR $3{ }^{+} \mathrm{CD} 4{ }^{+} \mathrm{Th} 1$ cells at the site of inflammation (Booth et al., 2002). It also plays an important role in $\mathrm{CD} 4{ }^{+} \mathrm{T}$-cell activation and maturation toward the Th1 phenotype (Michlmayr and McKimmie, 2014). Because our data show that TBI induced microglia activation resulted in an increase in CXCL10 production, and CD $4{ }^{+}$CXCR3 ${ }^{+}$ (Th1) cell infiltration and these events were attenuated by 50 $\mathrm{mg} / \mathrm{kg}$ GSK2656157, we monitored whether TBI-mediated CD4 ${ }^{+}$T-cell infiltration could be affected by knockdown of CXCL10. Interestingly, our FACS data and coimmunofluorescence data show that knockdown of CXCL10 by CXCL10 RNAi dramatically decreased $\mathrm{CD}^{+}{ }^{+}$Tbet $^{+}$Th1 (Fig. 6A) or $\mathrm{CD}^{+}{ }^{+} \mathrm{CXCR}^{+}{ }^{+}$(Fig. $6 B-D$ ) cell infiltration at the site of TBI injury. However, assessment of microglial activation after CXCL10 siRNA treatment by coimmunostaining using CD16/32 and Iba- 1 showed a moderate decrease in microglia activation and M1 polarization compared with TBI alone (Fig. 6-1 $A-C$, available at https://doi.org/10.1523/JNEUROSCI.0718-19.2019. f6-1). To confirm whether the intranasal delivery of CXCL10 siRNA is sufficient to decrease CXCL10 mRNA in the brain, we performed a CXCL10 qRT-PCR analysis with cortical brain tissue. Our data showed that intranasal delivery of CXCL10 siRNA was able to significantly decrease CXCL10 mRNA levels in the cortex compared with control (Fig. 6-1D, available at https:// doi.org/10.1523/JNEUROSCI.0718-19.2019.f6-1). Together, our 
A

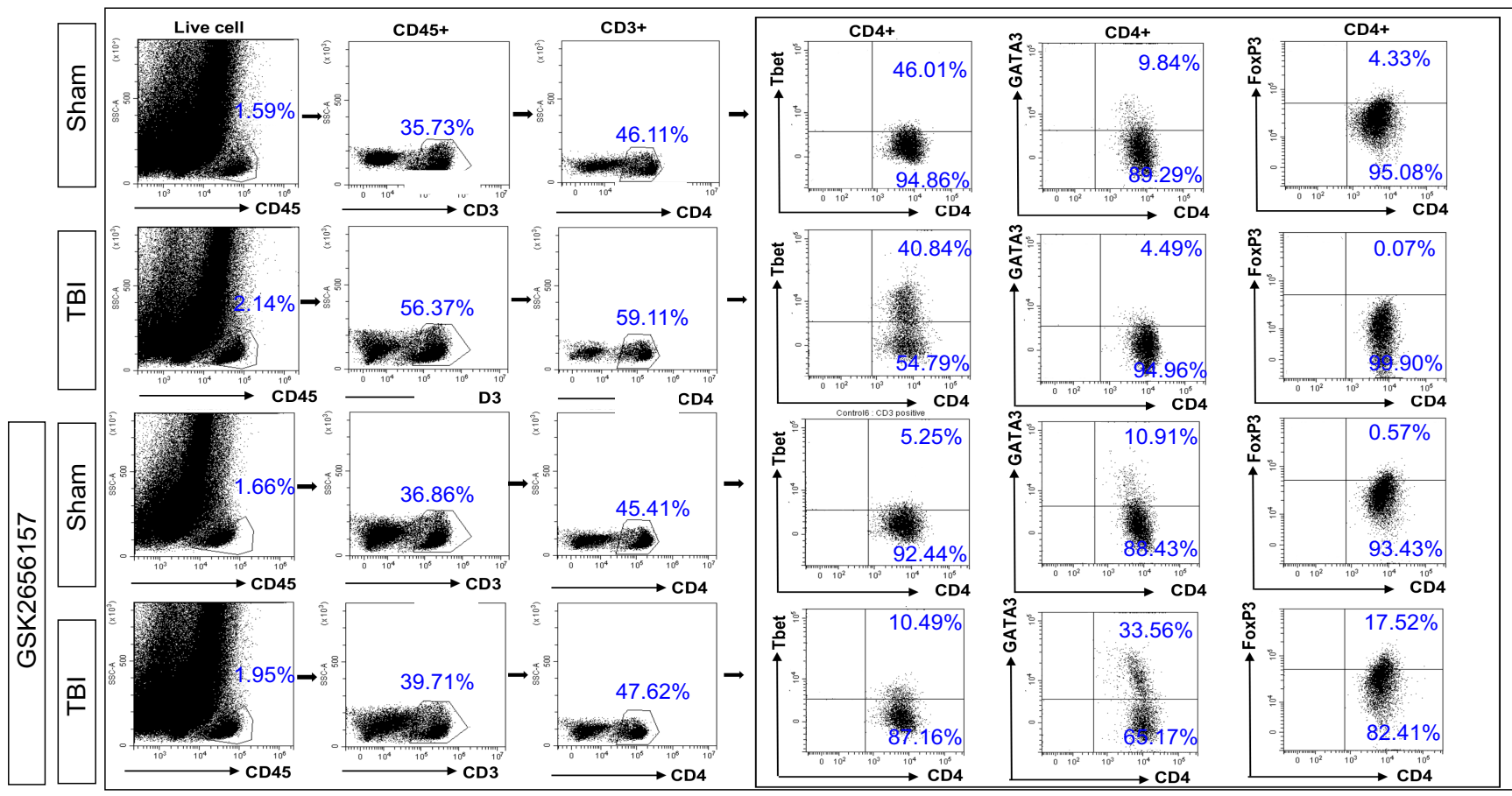

B
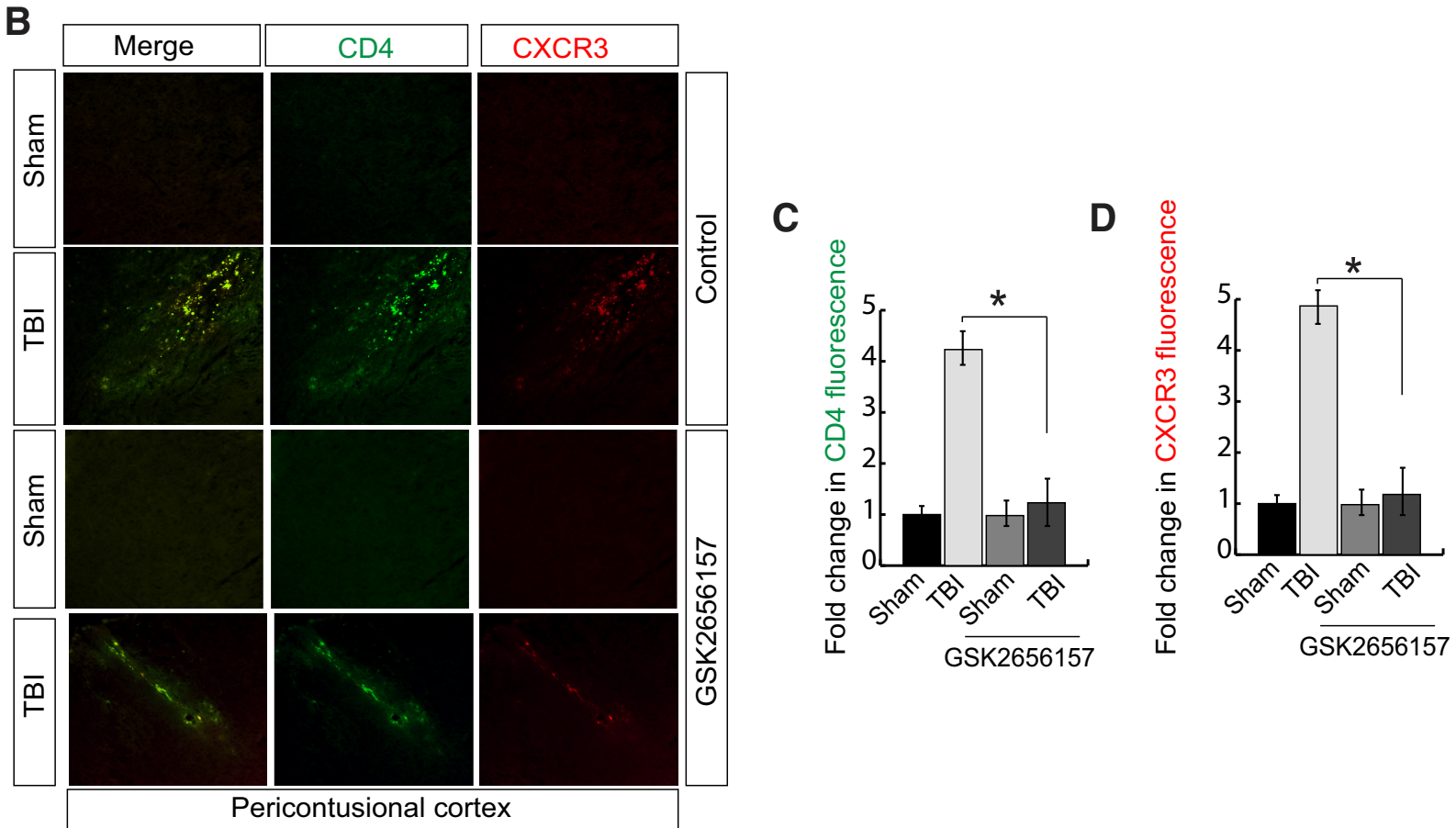

Figure 5. TBI induced Th1 T-cell infiltration was decreased with GSK2656157 treatment. Mice were subjected to TBI with or without $50 \mathrm{mg} / \mathrm{kg}$ GSK2656157 for $3 \mathrm{~d}$ and the following experiment were performed. $A$, FACS analysis was performed with purified brain mononuclear cells from CX tissues obtained from the brain at $3 \mathrm{~d}$ after sham or TBI, staining with CD45, CD3, CD4, Tbet, GATA3, and FoxP3 antibody. Representative scatterplots from five different experiments (using 3 male and 2 female mice in each group) shows the percentage of CD45+ cells gated on live cells (first column), CD3 + T cells gated on CD45 + cells (second column), CD4 + T cells in gated on CD3 + cells (third column), CD4 + Tbet + T cells (TH1) in CD4+ gated cells (fourth column), CD4+GATA3 + T cells (TH2) in CD4+ gated cells (fifth column), and CD4+FoxP3 + T cells (Treg) in CD4+ gated T lymphocyte cells (sixth column). B-D, The confocal microscopic analysis of CD4 and CXCR3 shows that CD4 and CXCR3 double-positive cells are decreased in GSK2656157-treated TBI pericontusional cortex compared with TBI. Representative figure $(\boldsymbol{B})$ is on the left, and the quantification on the right $(\boldsymbol{C}, \boldsymbol{D})$ shows binary analysis of the area of $C D 4$ and $C X C R 3$-expressing T cells by ImageJ analysis software; ${ }^{*} p<$ $0.05, n=5$ (3 male and 2 female mice in each group), one-way ANOVA, mean \pm SEM (Figure 5-1, available at https://doi.org/10.1523/JNEUROSCI.0718-19.2019.f5-1. 


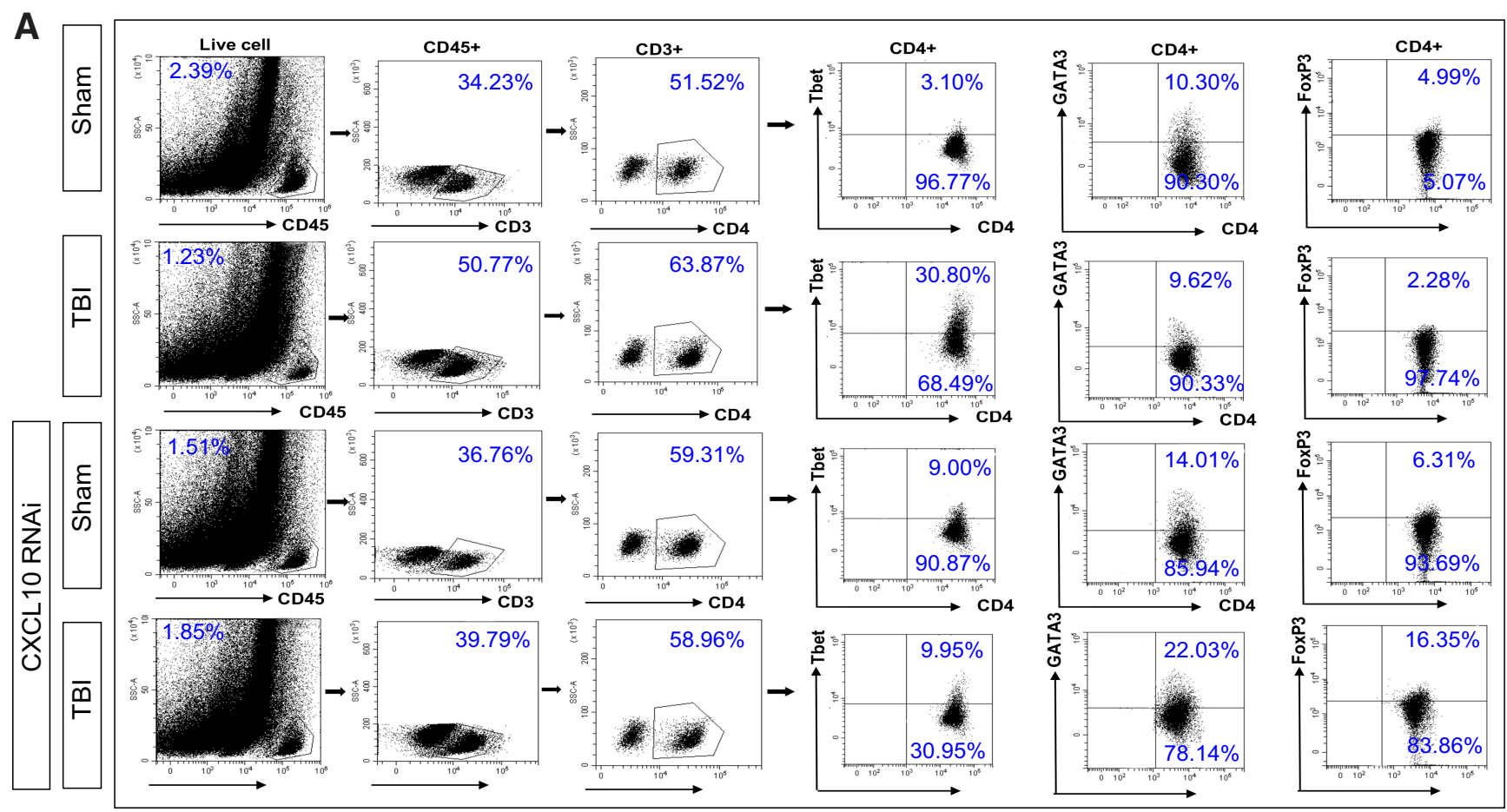

B
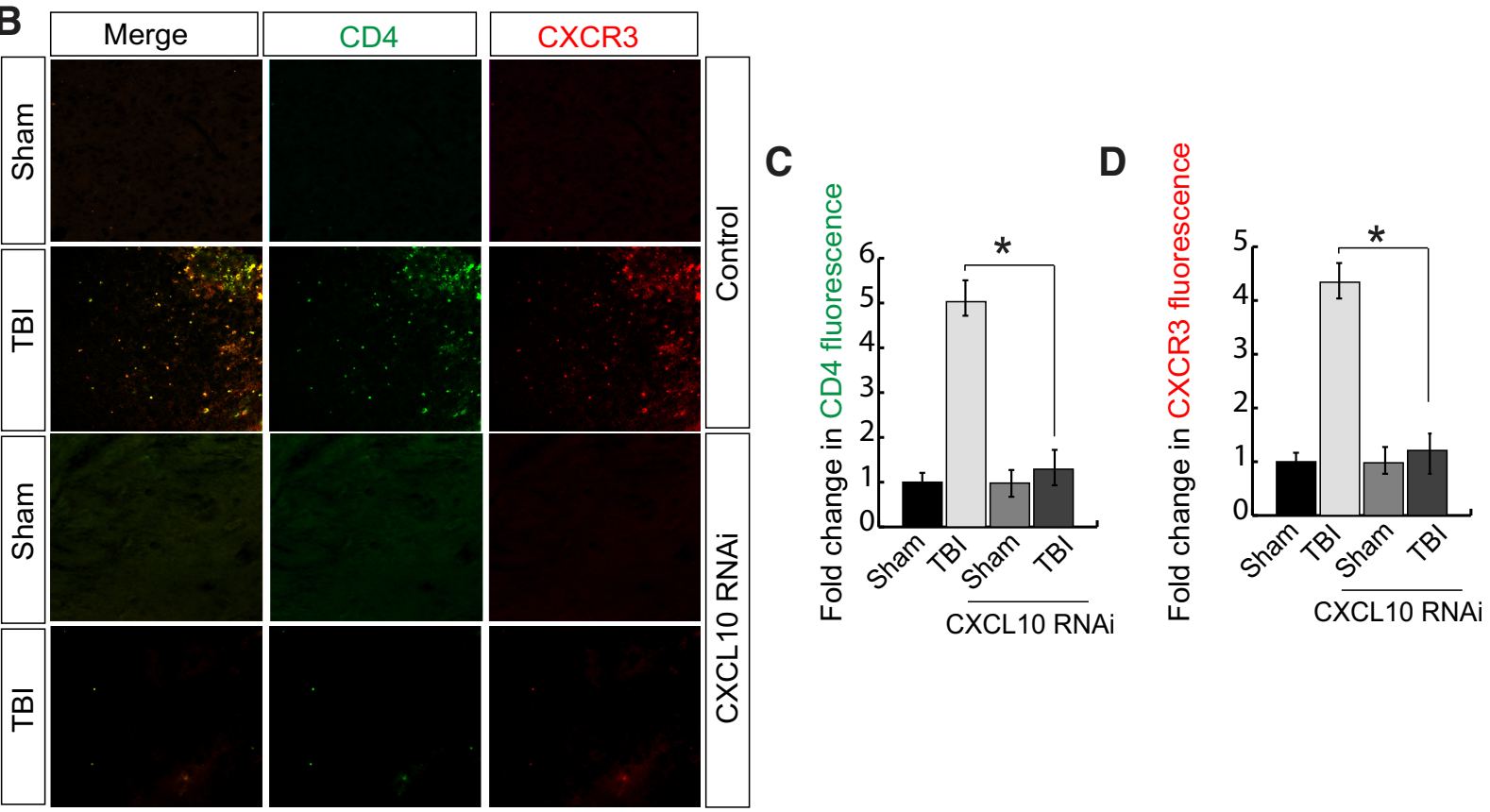

Figure 6. TBI-induced Th1 T-cell infiltration was attenuated by knocking down CXCL10 after TBI. Mice were subjected to TBI with or without administration of CXCL10-siRNA into the mouse brain by intranasal delivery before TBI. After $3 \mathrm{~d}$, the following TBI experiment was performed as follows. A, FACS analysis was performed with purified brain mononuclear cells from CX tissues obtained from the brain at $3 \mathrm{~d}$ after sham or TBI or treatment, staining with CD45, CD3, CD4, Tbet, GATA3, and FoxP3 antibody. Representative scatterplots from five different experiments (using 3 male and 2 female mice in each group) shows the percentage of CD45 + cells gated on live cells (first column), CD3 ${ }^{+} \mathrm{T}$ cells gated on CD45 ${ }^{+}$cells (second column), $\mathrm{CD} 4^{+} \mathrm{T}$ cells in gated on $\mathrm{CD} 3^{+}$cells (third column), $\mathrm{CD} 4^{+} \mathrm{Tbet}^{+} \mathrm{T}$ cells (TH1) in CD4 ${ }^{+}$gated cells (fourth column), $\mathrm{CD} 4^{+} \mathrm{GATA3}^{+} \mathrm{T}_{\text {cells }}(\mathrm{TH} 2)$ in CD4 ${ }^{+}$gated cells (fifth column), and CD4 ${ }^{+} \mathrm{FoXP3}^{+} \mathrm{T}$ cells (Treg) in CD4 ${ }^{+}$gated T lymphocyte cells (sixth column). $\boldsymbol{B}-\boldsymbol{D}$, The confocal microscopic analysis of CD4 and CXCR3 shows that CD4 and CXCR3 double-positive cells are decreased in CXCL10-siRNA-treated TBI pericontusional cortex compared with TBI. Representative figure (B) is on the left, and the quantification on the right $(\boldsymbol{C}$, D) shows binary analysis of the area of CD4 and CXCR3-expressing T cells by ImageJ analysis software; ${ }^{*} p<0.05, n=5$ ( 3 male and 2 female mice in each group), one-way ANOVA, mean \pm SEM (Figure 6-1, available at https://doi.org/10.1523/JNEUROSCI.0718-19.2019.f6-1). 

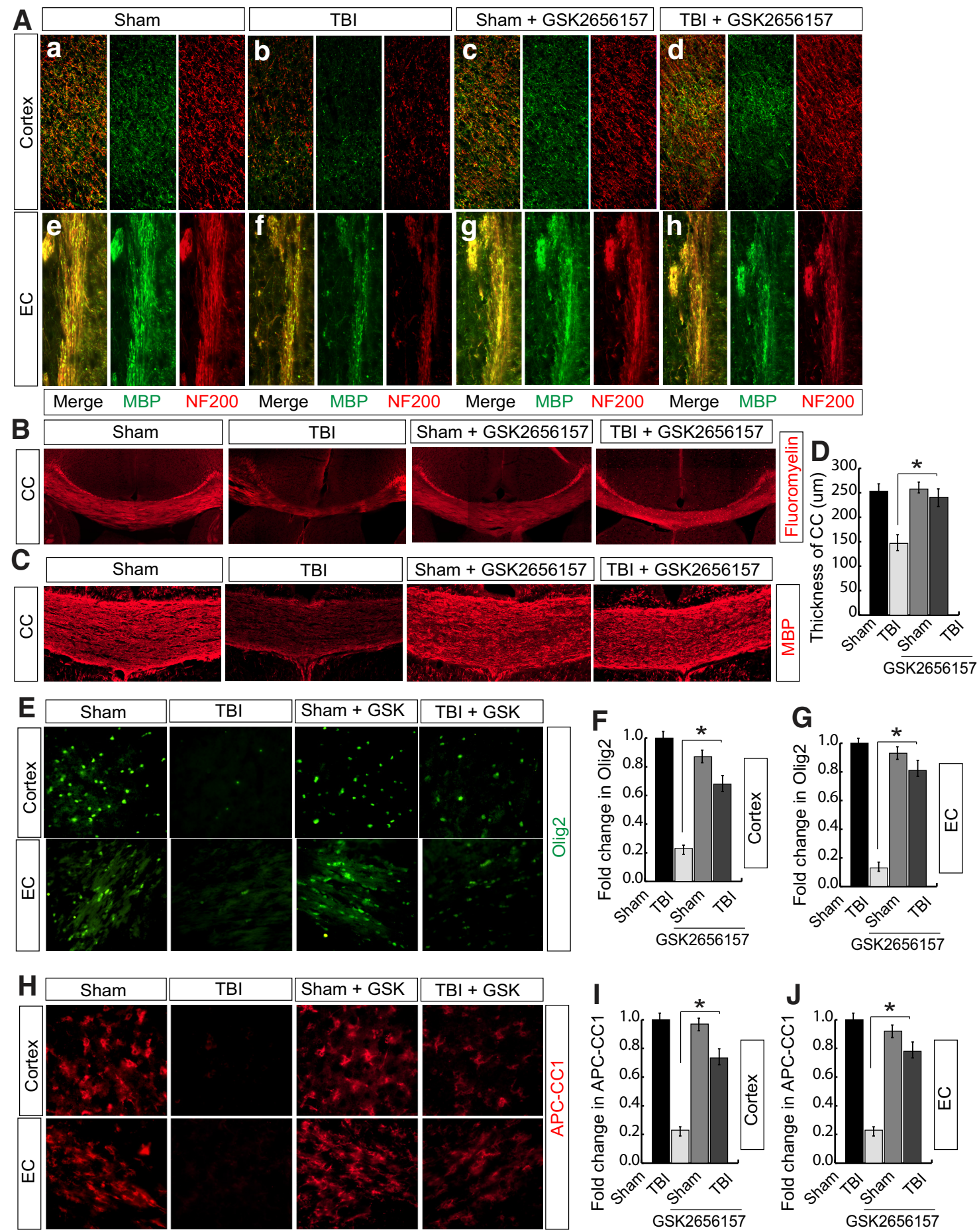

Figure 7. GSK2656157 treatment increased myelination and decreased white matter damage after TBI. Mice were subjected to TBI with or without $50 \mathrm{mg} / \mathrm{kg}$ GSK2656157 for $3 \mathrm{~d}$, and

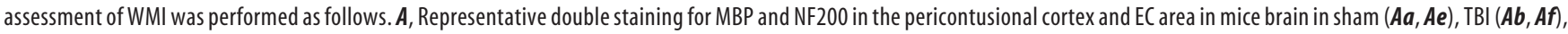
sham with GSK2656157 treatment ( $\boldsymbol{A C}, \boldsymbol{A g})$, TBI with GSK2656157 treatment $(\boldsymbol{A d}, \boldsymbol{A} \boldsymbol{h}) . \boldsymbol{B}-\boldsymbol{D}$, Representative FM $(\boldsymbol{B})$ and MBP staining $(\boldsymbol{C}, \boldsymbol{D})$ in $C(\boldsymbol{C}$ area show changes in $C(\mathrm{C}$ thickness in mice brain subjected to TBI with or without GSK2656157 treatment for $3 \mathrm{~d}$. Quantitation of $C\left(\mathrm{C}\right.$ thickness by ImageJ analysis software with MBP staining $(\boldsymbol{D})$ is on the right. ${ }^{*} p<0.05, n=$ 5 ( 3 male and 2 female mice in each group), one-way ANOVA, mean \pm SEM. E-G. The confocal microscopic analysis of Olig2 shows that OPCs are decreased in TBI pericontusional cortex and EC area compared with sham. Olig2-positive cells are increased in GSK2656157-treated TBI pericontusional cortex and EC area compared with TBI alone. Representative figure (E) is on the left, and the quantification on the right $(\boldsymbol{F}, \boldsymbol{G})$ shows binary analysis of Olig2-expressing cells by ImageJ analysis software; ${ }^{*} p<0.05, n=5$ ( 3 male and 2 female mice in each group), one-way ANOVA, mean \pm SEM. $\boldsymbol{H}-\boldsymbol{J}$, The confocal microscopic analysis of APC-CC1 shows that mature oligodendrocytes are decreased in TBI pericontusional cortex and EC area compared with sham. Further, APC-CC1-positive cells are increased in GSK2656157-treated TBI pericontusional cortex and EC area compared with TBI alone. Representative figure $(\boldsymbol{H})$ is on the left and the quantification on the right $(I, J)$ shows binary analysis of Olig2-expressing cells by ImageJ analysis software; ${ }^{*} p<0.05, n=5$ ( 3 male and 2 female mice in each group), one-way ANOVA, mean \pm SEM (Figure 7-1, available at https://doi.org/10.1523/JNEUROSCI.0718-19.2019.f7-1). 
data suggest that increased CXCL10 production may play a central role in the T-cell infiltration as a feedforward loop following TBI.

\section{Treatment with GSK2656157, knockdown of PERK or CXCL10 decreased demyelination, WMI, and rescued tissue loss after TBI} It has been reported that an increase in the number of M1 microglial cells following TBI is strongly correlated with the severity of WMI, whereas the M2 phenotype may be neuroprotective (G. Wang et al., 2013). Therefore, we expect that GSK2656157 mediated priming of microglia toward the beneficial M2 phenotype after TBI may protect against WMI. To verify our hypothesis we assessed the integrity of myelin and axons with immunostaining against MBP and neurofilament heavy chain, NF200, in the CX and EC at $3 \mathrm{~d}$ after TBI with or without treatment with GSK2656157 or intranasal PERK siRNA. In both sham-operated groups, the MBP and NF200 signals in the pericontusional cortex or CX (top row) and EC (bottom row) were high (Fig. 7A and Fig. 7-1A-E, available at https://doi.org/10.1523/JNEUROSCI.071819.2019.f7-1). However, both the MBP and NF200 signals were extremely low in the TBI CX and EC, indicating axon loss and a hypomyelination within these regions (Fig. 7A and Fig. 7-1 $A-E$, available at https://doi.org/10.1523/JNEUROSCI.0718-19.2019.f7-1). Interestingly the expression of both MBP and NF200 were remained near sham levels after GSK2656157 treatment (Fig. 7A and Fig. 7-1 A,B, available at https://doi.org/10.1523/ JNEUROSCI.0718-19.2019.f7-1) or PERK siRNA treatment (Fig. 7-1C-E, available at https://doi.org/10.1523/JNEUROSCI.071819.2019.f7-1) compared with TBI alone and was also correlated with the MBP and NF200 immunofluorescence in CX and EC areas (Fig. 7-1 A,B,D,E, available at https://doi.org/10.1523/ JNEUROSCI.0718-19.2019.f7-1), suggesting the promotion of maturation of myelin components in the brain.

We further monitored whether a decrease in MBP expression after TBI was positively correlated with the thickness of CC and FM staining. We found that TBI leads to a significant decrease in the thickness of CC (stained with MBP; Fig. 7C,D, and Fig. 7-1F,G, available at https://doi.org/10.1523/ JNEUROSCI.0718-19.2019.f7-1) and FM staining (Fig. 7B). However, treatment with $50 \mathrm{mg} / \mathrm{kg}$ GSK2656157 protected the thickness of CC (Fig. 7C,D) and rescued FM staining (Fig. 7B). Similarly, treatment of PERK siRNA prevented the loss of CC thickness (Fig. 7-1F, G, available at https://doi.org/10.1523/ JNEUROSCI.0718-19.2019.f7-1) after TBI; suggesting that PERK inhibition or its downregulation significantly improve myelination following TBI.

Moreover, to determine whether WMI due to TBI is associated with T-cell infiltration we performed intranasal CXCL10 knockdown by siRNA immediately after TBI. Consistent with data resulted from GSK2656157 and PERK siRNA treatment, CXCL10 knockdown partially restores the expression of both the MBP and NF200 (Fig. 7-2A,B, available at https://doi.org/ 10.1523/JNEUROSCI.0718-19.2019.f7-2) and MBP and NF200 immunofluorescence in the CX (Fig. 7-2 B, available at https://doi.org/ 10.1523/JNEUROSCI.0718-19.2019.f7-2) compared with TBI alone. MBP expression after TBI was also found to be positively correlated with the thickness of CC and FM staining after CXCL10 knockdown. We found that TBI leads to a significant decrease in the thickness of CC (Fig. 7-2 D,E, available at https://doi.org/10.1523/ JNEUROSCI.0718-19.2019.f7-2) and FM staining (Fig. 7-2 J, available at https://doi.org/10.1523/JNEUROSCI.0718-19.2019.f7-2). However, treatment with CXCL10 siRNA partly maintained the thickness of CC and rescued FM staining (Fig. 7-2C,E, available at
https://doi.org/10.1523/JNEUROSCI.0718-19.2019.f7-2) after TBI.

Considering that loss of oligodendrocytes $(\mathrm{OL})$ contribute to impairment in myelin formation, we monitored whether OLs and oligodendrocyte precursor cells (OPCs) are affected by TBI with or without GSK2656157 treatment. Similar to the demyelination data, our confocal data for APC-CC1 and Olig2 staining show that the number of Olig2 (OPC marker; Fig. 7E-G) and APC-CC1 (mature OL marker; Fig. 7H-J) stained cells were rescued in CX (top rows) and EC areas (bottom rows) after GSK2656157 treatment compared with TBI alone. Together our data suggest that ER stress-mediated activation of neuroinflammation might play a significant role in TBI mediated WMI and loss OLs.

The potential for identifying microstructural damage in TBI patients and experimental animal model of TBI can be monitored by DTI analysis (Bigler and Bazarian, 2010; Long et al., 2015), which mostly functions through water's diffusion to yield measures of tissue integrity (Basser et al., 1994a,b). White matter bundles are composed of densely packed, collinearly organized axons, and when net diffusion occurs along the fibers' axis of orientation, it is said to be anisotropic. However, WMI may increase diffusion in all directions, making it more isotropic. By evaluating these properties, DTI provides information on the health and architecture of brain white matter tracts. FA is an index of DTI analysis and represents diffusion restricted to a single direction, and higher FA values is an index indicating greater integrity of white matter tracts. $\mathrm{RD}$ is an index of diffusivity perpendicular to the axon fiber direction, and higher RD values indicate abnormalities in myelination along the axonal tracts (Alexander et al., 2007). Similar to previous findings (Narayana, 2017; Pischiutta et al., 2018) we also found that compared with sham mice, TBI mice ( $21 \mathrm{~d}$ after CCI) exhibited significant decreases in FA and increases in RD in the CC and EC in the hemisphere ipsilateral to the contusion (Fig. 8A-E). However, $50 \mathrm{mg} / \mathrm{kg}$ of GSK2656157 or intranasal administration of CXCL10 siRNA leads to a significant recovery in FA and a decrease in RD after TBI (Fig. 8A-E). These results are consistent with our other findings. Together our data suggest that neuronal ER stress-mediated activation of neuroinflammation might play a critical role in TBI-mediated WMI and confirms that inhibition of TBI mediated neuronal PERK activation by GSK2656157 can reduce brain tissue loss and white matter damage after TBI.

\section{Treatment with GSK2656157 and CXCL10 siRNA rescue tissue loss after TBI}

To evaluate the potential neuroprotective effect of $50 \mathrm{mg} / \mathrm{kg}$ GSK2656157 and the depletion of CXCL10 using CXCL10 siRNA after TBI, we measured the extent of tissue loss by staining evenly spaced brain sections by Cresyl violet. Three days post-TBI, we found distinct cavitation in the injured cerebral hemisphere and that were significantly reversed by treatment with $50 \mathrm{mg} / \mathrm{kg}$ GSK2656157 and administration of intranasal CXCL10 siRNA after TBI (Fig. $8 F, G$ ). However, the reversal of tissue loss was more with GSK2656157 compared with CXCL10 siRNA, suggesting that inhibition of TBI-mediated neuronal PERK activation by GSK2656157 might be a promising therapeutic agent that can reduce brain tissue loss and white matter damage after TBI.

\section{Treatment with GSK2656157 and PERK siRNA improved anxiety and depressive-like disorder after TBI}

The TBI-induced increased risk of anxiety and depressive disorders are associated with inflammatory changes in brain regions 

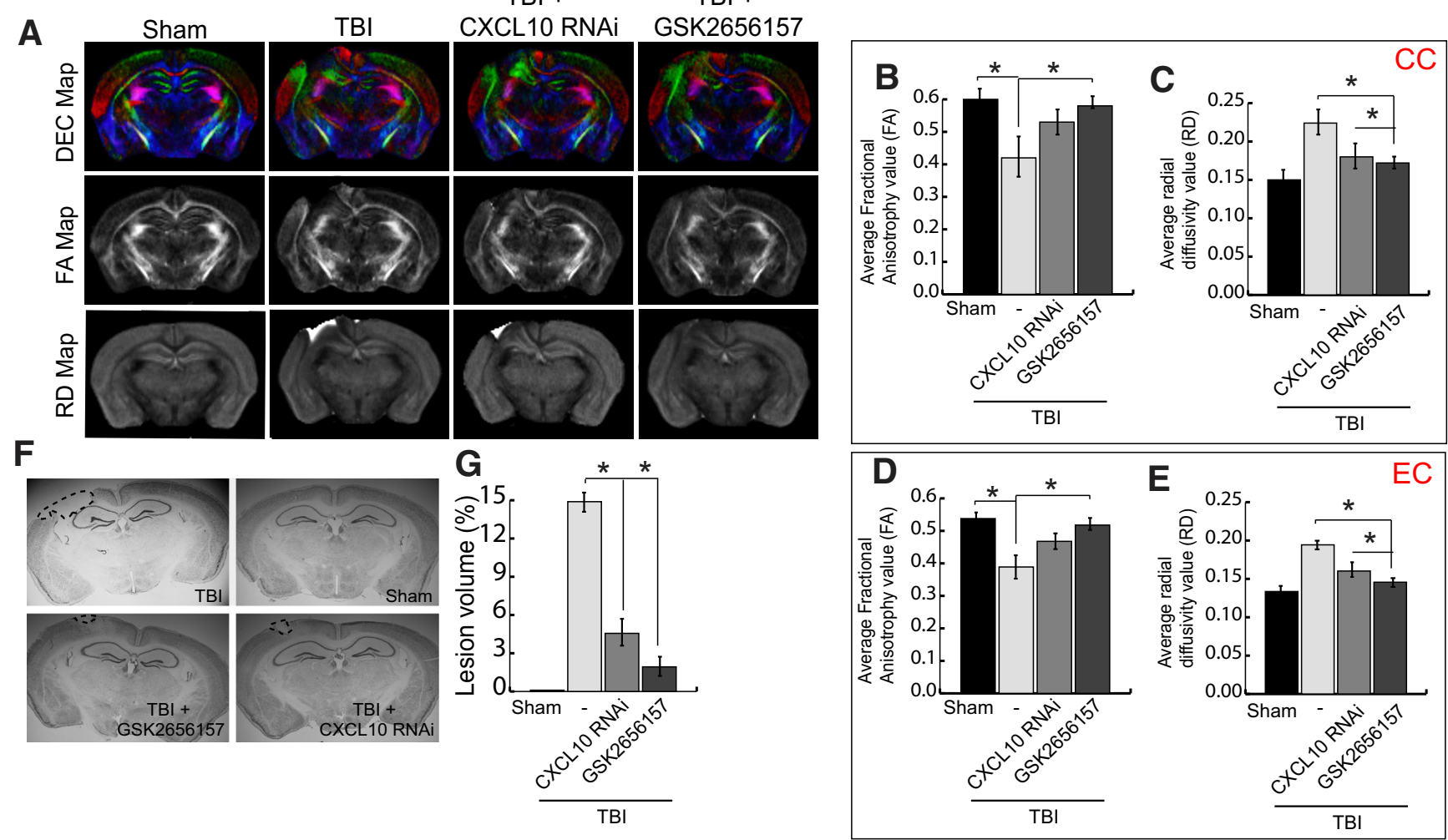

Figure 8. Treatment with GSK2656157 or CXCL10 siRNA reduced TBI lesion volume and WMI as measured by ex vivo DTI. Assessment of WMI was performed by ex vivo MRI $21 \mathrm{~d}$ after TBI or sham operation. Panel A shows representative RD, FA and DEC maps centered on the site of contusion. Treatment groups ( + CXCL10 siRNA) and ( + GSK2656157) were treated daily for 3 weeks following TBI. The colors of the DEC maps indicate the principle axis of water diffusion (red, mediolateral; green, dorsoventral; blue, anteroposterior). $\boldsymbol{B}-\boldsymbol{E}$, Quantification of average FA and RD values in the $C C$ and EC area of the ipsilateral hemispheres shows that FA and RD values were rescued after either GSK2656157 or CXCL10 siRNA treatment. ${ }^{*} p<0.05, n=5$ ( 3 male and 2 female mice in each group), one-way ANOVA, mean \pm SEM. F, G, (resyl violet-stained coronal sections showed a sham, TBI, TBI + 50 mg/kg GSK265615 and TBI + CXCL10 siRNA mice with brain tissue loss at the impact site at $3 \mathrm{~d}$ post-injury. $\boldsymbol{F}$, Representative images of cresyl violet-stained coronal sections and $(\boldsymbol{G})$ quantitative analysis shows the percentage of lesion volume $3 \mathrm{~d}$ post-injury. ${ }^{*} p<0.05, n=5(3$ male and 2 female mice in each group), one-way ANOVA, mean \pm SEM.

(Rodgers et al., 2014; Broussard et al., 2018). Because our data show that $50 \mathrm{mg} / \mathrm{kg}$ GSK2656157 or PERK knockdown reduced neuroinflammation by regulating microglia polarization and $\mathrm{T}$-cell infiltration, it is possible that anxiety and depressive-like behavior will be improved in mice after treatment with GSK2656157 or PERK siRNA.

Considering that mice have a natural aversion to the brightly lit center of an open field, comparison of the percentage of time spent in the center versus the periphery of the field indicates anxiety-related behavior. We found that the total movement time during the session was similar between sham and TBI groups of mice (Fig. 9A and Fig. 9-1 A, available at https://doi.org/10.1523/ JNEUROSCI.0718-19.2019.f9-1); indicating that there is no major deficiency in locomotor activities in either group. However, the TBI-mice spent significantly less amount of time in the center compared with that of sham mice (Fig. $9 B$ and Fig. 9- $1 B$, available at https://doi.org/10.1523/JNEUROSCI.0718-19.2019.f9-1). These data suggest that TBI mice exhibited more anxiety-like behavior compared with sham mice. Interestingly, TBI mice treated with $50 \mathrm{mg} / \mathrm{kg}$ GSK2656157 or PERK siRNA spent a greater percentage of time in the central zone compared with TBI mice (Fig. 9-1 B, available at https://doi.org/10.1523/JNEUROSCI.0718-19.2019.f9-1), suggesting that inhibition of PERK by GSK2656157 or knockdown of PERK by PERK siRNA improves anxiety-like behavior following TBI. The tail suspension test and forced swim test are used to monitor depressive-like behavior in mice, with greater periods of immobility correlating with depression. We found that the period of immobility for TBI-mice was significantly longer than sham-mice during tail suspension (Fig. $9 C$ and Fig. 9-1C, available at https://doi.org/10.1523/JNEUROSCI.0718-19.2019.f9-1) and forced swim tests (Fig. 9D and Fig. 9-1 D, available at https:// doi.org/10.1523/JNEUROSCI.0718-19.2019.f9-1); these data suggest that TBI mice exhibited depressive-like behavior. However, TBI mice treated with GSK2656157 or PERK siRNA were significantly more active during tail suspension (Fig. 9C and Fig. 9-1C, available at https://doi.org/10.1523/JNEUROSCI.0718-19.2019.f9-1) and forced swim test (Fig. $9 D$ and Fig. 9-1D, available at https:// doi.org/10.1523/JNEUROSCI.0718-19.2019.99-1) compared with untreated mice.

To exclude the possibility that use of ketamine/xylazine as an anesthetic during CCI surgery directly affects neuropsychiatric behaviors, including anti-depressive behavior we performed the neurobehavioral experiment with $50 \mathrm{mg} / \mathrm{kg}$ GSK2656157 using the relatively short-lasting anesthetic, isoflurane, during CCI surgery as described in the methods. Our data showed that GSK2656157 significantly reduced the anxiety-like behavior in TBI mice measured by open field, tail suspension and forced swim test, indicating that GSK2656157 treatment improves depressive-like behavior regardless of using isoflurane (Fig. 9-1E-H, available at https://doi.org/10.1523/ JNEUROSCI.0718-19.2019.f9-1) or xylazine/ketamine (Fig. 9A-D) as anesthetic agent. Together our data proves that inhibition of PERK by GSK2656157 treatment or knockdown of PERK by PERK siRNA improves depressive-like behavior following TBI. 

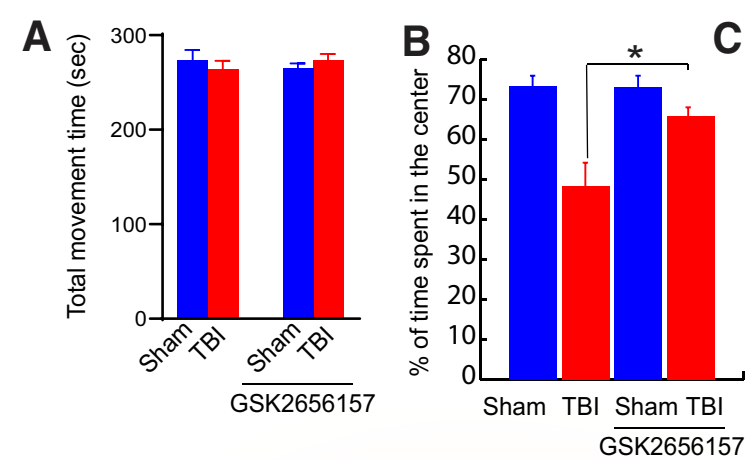

Open Field Test

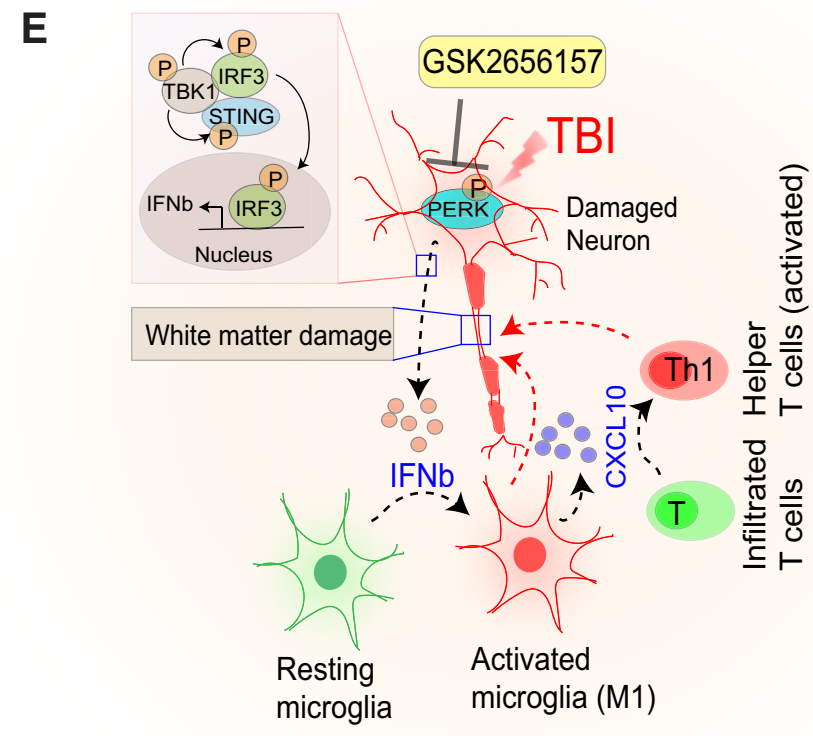

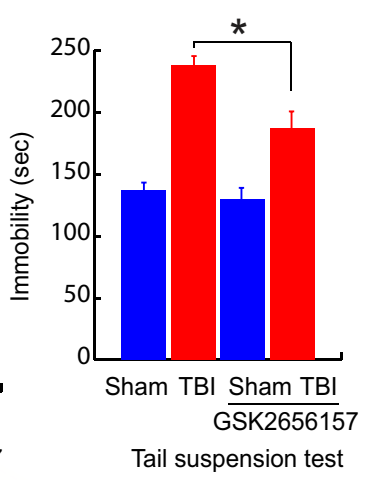

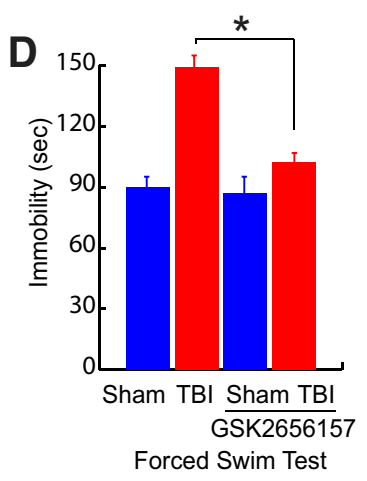

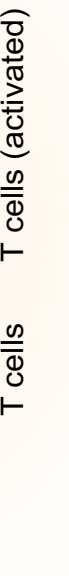

Figure 9. Treatment with GSK2656157 improved anxiety and depressive-like disorder after TBI. Mice were subjected to TBI with or without GSK2656157 daily for 3 weeks, and the following behavioral experiment was performed. $\boldsymbol{A}, \boldsymbol{B}$, TBI mice treated with GSK2656157 showed similar movement time ( $\boldsymbol{A})$; however, spent significantly more percentage of time in the center ( $\boldsymbol{B})$ compared with TBI mice ( $n=10,5$ male and 5 female mice in each group; one-way ANOVA, mean \pm SEM, ${ }^{*} p<0.05$ ). C, The immobility induced by TBI was rescued in mice treated with GSK2656157 significantly during tail suspension test $\left(n=10,5\right.$ male and 5 female mice in each group; one-way ANOVA, mean $\left.\pm S E M,{ }^{*} p<0.05\right)$. $\boldsymbol{D}$, The increase in floating time was significantly decreased in mice treated with GSK2656157 following TBI during Forced swim test $\left(n=10,5\right.$ male and 5 female mice in each group; one-way ANOVA, mean \pm SEM, $\left.{ }^{*} p<0.05\right)$. $\boldsymbol{E}$, A model is showing how neuronal ER stress pledge neuroinflammation via activating STING-TBK1-IRF3-type I IFN pathway leading to WMI and anxiety and depressive-like behavior following TBI. TBI leads to increased PERK activation in neuron leading to STING activation. Activated STING forms aggregate with TBK1 and IRF3 leading to activation and translocation of IRF 3 to the nucleus to trigger transcription of IFN $\beta$, which promote microglial activation and polarization to M1 proinflammatory phenotype. As a result, the increased proinflammatory chemokines and chemokine, such as CXCL10 increased Th1 cell infiltration by serving as the ligand and chemoattractant for CXCR3 + Th1 cells. The activation of M1 microglia and infiltration of Th1 cells resulted in WMI and increased anxiety and depressive-like behavior following TBI. Targeting PERK mediated neuronal ER stress through GSK2656157 confers protection after TBI by preventing the proinflammatory cascade shifting M1 microglia to the wound-healing anti-inflammatory M2 phenotype (Figure 9-1, available at https://doi.org/10.1523/JNEUROSCI.0718-19.2019.f9-1).

\section{Discussion}

The pathology of TBI largely results from the aberrant activation of inflammatory cells such as microglia and/or infiltrated T cells after disruption of the blood-brain barrier following. Here we show that persistent ER stress in neurons serves as a potential mechanism to trigger inflammatory cascades of microglial polarization to M1 and conversion of infiltrated T cells to Th1 (Fig. $9 E)$. In a previous study, we determined that atypical activation of PERK protein in the neuron is the major contributor of aberrant ER stress after TBI. In this study, we determined that blocking activation of neuronal PERK phosphorylation or knockdown of PERK by PERK siRNA prevented the aberrant neuroinflammation and white matter injury that resulted in anxiety and depressive-like behavior. As a part of the mechanism, we found that an excess secretion of neuronal IFN $\beta$ by activating STINGTBK1-IRF3 signaling following aberrant PERK activation by inducing its phosphorylation, enforced activation of M1 microglia by triggering STAT1 signaling. Activated microglia secreted a proinflammatory chemokine CXCL10, which stimulated the T-cell infiltration by serving as the ligand and chemoattractant for $\mathrm{CXCR}^{+}{ }^{+}$Th1 cells. Thus, targeting PERK-P using GSK2656157 appears to be essential to mitigate neuroinflammation and behavioral abnormalities following TBI.

A recent study showed that human brain trauma patients had enhanced expression of type-1 IFN; suggesting that type-1 IFN signaling may potentially influence the clinical outcome in TBI 
patients (Karve et al., 2016). In fact, a previous study with an experimental TBI animal model showed that reduced type 1 IFN signaling reduces inflammation after TBI (Karve et al., 2016). It was recently reported that type I interferon receptor signaling of neurons could regulate microglia activation during Viral Encephalitis (Chhatbar et al., 2018). Here we provide compelling evidence that induction of neuronal ER stress is responsible for triggering IFN $\beta$ and reducing ER stress by inhibiting PERK phosphorylation (by GSK2656157) or PERK knockdown prevents aberrant activation of IFN $\beta$ and subsequent activation of microglia and infiltration of T cells following TBI. However, it is important to mention that a physiological level of IFN $\beta$ is required for normal brain functions. Previously it was shown that the type I interferon IFN $\beta$ negatively affected brain function during aging (Baruch et al., 2014), and on the other hand, IFN $\beta$ can serve a protective function and is used to dampen inflammation in active, relapsing multiple sclerosis (The IFN $\beta$ Multiple Sclerosis Study Group, 1993). Additionally, the lack of IFN $\beta$ signaling in neurons resulted in Lewy body and Parkinson's disease-like dementia in mice (Ejlerskov et al., 2015). Together, these studies along with our current finding suggest that the relative levels of IFN $\beta$ and the context in which they act have a profound effect on neuroinflammation under physiological or pathological conditions (Deczkowska et al., 2017).

A growing body of evidence shows that persistent inflammation is the crucial factor that leads to enduring white matter degeneration for many years after TBI in humans and experimental animal models; clearly demonstrating an association between chronic microglial activation after injury and neurodegeneration (Johnson et al., 2013). Similarly, in a mouse CCI model, inflammatory changes were accompanied by WMI and loss of myelin (Loane et al., 2014). However, the underlying mechanisms driving this progressive loss of white matter and its correlation with neuroinflammation remain poorly understood. The M1- and M2-like microglia and macrophages work in concert to fine-tune inflammatory responses, scavenge debris, and promote remodeling and repair after TBI; thereby contributing to successful wound healing and promoting a return toward homeostasis after injury. Therefore, considering the M1/M2 paradigm, it remained controversial whether targeting microglial cells has a beneficial or detrimental outcome in TBI. An improved understanding of the dynamic equilibrium between M1 and M2 microglia is necessary for post-trauma recovery and help ameliorate WMI in trauma victims. Here, our study showed that IFN $\beta$ released from damaged neurons is essential for NF- $\kappa \mathrm{B}$ and STAT1 activation for promoting microglial activation to the proinflammatory M1 phenotype, which, in turn, exacerbates WMI and demyelination. The inhibition of ER stress-mediated IFN $\beta$ release after administration of GSK2656157 decreased STAT1 activation, and increased STAT3 and STAT6 activation and M2 microglia polarization, associated with tissue repair. Moreover, the release of CXCL10 from M1-type microglial cells served as a major player for Th1 T-lymphocyte infiltration. Our study provides direct evidence that treatment with GSK2656157 causes a dramatic decrease in Th1 and increase in Th2 and Treg infiltration following TBI. Thus, it is possible that GSK2656157 mediated increase IL- 4 and IL10 production by Th2 and Treg, respectively, can skew microglia/macrophage function toward the M2 phenotype. Our data are also supported by a recent study showing inhibition of type I IFN signaling in mice show greater M2polarization compared with Wt mice after TBI (Karve et al., 2016). Together, our study proposes that suppression of neuronal ER stress-mediated IFN $\beta$ release by GSK2656157 after TBI could reinforce the fine balance between protective and harmful effects of microglial activation; thereby contributing to decreased WMI and successful wound healing, and highlighting the therapeutic potential of GSK2656157 for TBI treatment. Recently another study showed that the administration of GSK2656157 targets the receptor-interacting protein kinase 1 (RIPK1) independently of PERK phosphorylation in peripheral tissues (Rojas-Rivera et al., 2017). However, our study shows that administration of GSK2656157 has no influence on RIPK1 in the brain after TBI (data not shown), suggesting that the effect of GSK2656157 toward RIPK1 could be tissue-specific, although the inhibition of PERK phosphorylation is universal. Moreover, consistent with studies related with GSK2656157, our study showed that PERK siRNA not only decreased TBK-1, IRF-3, STING phosphorylation, and IFN $\beta$ expression but also significantly decreased M1 microglia polarization after TBI, with a shift toward M2 polarization, decreased CXCL10 production, Th1 infiltration in the brain and WMI. In addition to, similar to GSK2656157 treatment of PERK siRNA improves depressive-like behavior following TBI. Therefore, our study points to GSK2656157 as a promising therapeutic agent against TBI pathology.

The recent findings of Ndode-Ekane et al. (2018) suggests that acute infiltration of T cells into the brain parenchyma after TBI is a contributing factor to poor post-injury recovery. On the other hand, in other models of CNS injury, T cells have been found to confer neuroprotection (Moalem et al., 1999; Jones et al., 2015). Thus, it remains unclear what role(s) T-lymphocytes play in postTBI functional outcome, secondary inflammatory processes, and trauma-associated wound-healing responses. Th1 lymphocytes, which secrete proinflammatory cytokines while Th2 lymphocytes produce anti-inflammatory cytokines such as IL-4 and IL-10. Here, our study provides direct evidence that treatment with GSK2656157 causes a dramatic decrease in Th1 and increase in Th2 and Treg infiltration and anti-inflammatory cytokines IL-4, IL-10, and IL-13 following TBI. IL-4 and IL-10 play a central role in the differentiation of antigen-stimulated naive T cells into Th2 cells (Abbas et al., 1996). Our data are also supported by a recent study showing that loss of IL-4 signaling in KO mice was associated with worse outcomes (increased infarct volume, neurological score, inflammation) and decreased Th1/Th2 ratio after TBI compared with $\mathrm{Wt}$, and this was reversed by giving exogenous IL-4 (Xiong et al., 2011).

Recruitment of T cells into the brain parenchyma is precisely regulated by different chemokine expression from microglial cells responding to particular noxious stimuli (Cheeran et al., 2003). Moreover, Activated microglia are capable of inducing myelin antigen-specific T lymphocyte activation (Cash et al., 1993). The release of CXCL10 from M1-type microglial cells served a vital function for the activation and infiltration of Th1 CD4 T cell. Our study provides direct evidence that knockdown of CXCL10 cause a dramatic decrease in CD $4{ }^{+} \mathrm{Tbet}^{+} \mathrm{Th} 1$, and increased Th2, Treg, and T-cell infiltration following TBI. However, knockdown of CXCL10 only partially recovered WMI, increased CC thickness, and lesion volume compared with treatment with GSK2656157 highlighting the better therapeutic potential of GSK2656157 for TBI treatment. A possible explanation for this observation may be because neuronal ER stress is upstream and directly involved in the innate immune system and CXCL10 induction following TBI.

In addition, mood and anxiety disorders account for a significant part of the disability resulting from TBI of varying severity (Rodgers et al., 2014; Broussard et al., 2018). Clinical observations suggest that a close relationship exists between proinflam- 
matory cytokines and major depression. Although there is an urgent need to study mechanisms and treatment alternatives for these conditions, our study may provide further insight into the pathophysiology of these disorders in the population as a whole.

\section{References}

Abbas AK, Murphy KM, Sher A (1996) Functional diversity of helper T lymphocytes. Nature 383:787-793.

Abdullah A, Zhang M, Frugier T, Bedoui S, Taylor JM, Crack PJ (2018) STING-mediated type-I interferons contribute to the neuroinflammatory process and detrimental effects following traumatic brain injury. J Neuroinflammation 15:323.

Aihara N, Hall JJ, Pitts LH, Fukuda K, Noble LJ (1995) Altered immunoexpression of microglia and macrophages after mild head injury. J Neurotrauma 12:53-63.

Alexander AL, Lee JE, Lazar M, Field AS (2007) Diffusion tensor imaging of the brain. Neurotherapeutics 4:316-329.

Almeida-Suhett CP, Prager EM, Pidoplichko V, Figueiredo TH, Marini AM, Li Z, Eiden LE, Braga MF (2014) Reduced GABAergic inhibition in the basolateral amygdala and the development of anxiety-like behaviors after mild traumatic brain injury. PLoS One 9:e102627.

Aroniadou-Anderjaska V, Pidoplichko VI, Figueiredo TH, Almeida-Suhett CP, Prager EM, Braga MF (2012) Presynaptic facilitation of glutamate release in the basolateral amygdala: a mechanism for the anxiogenic and seizurogenic function of GluK1 receptors. Neuroscience 221:157-169.

Balachandran S, Thomas E, Barber GN (2004) A FADD-dependent innate immune mechanism in mammalian cells. Nature 432:401-405.

Baruch K, Deczkowska A, David E, Castellano JM, Miller O, Kertser A, Berkutzki T, Barnett-Itzhaki Z, Bezalel D, Wyss-Coray T, Amit I, Schwartz M (2014) Aging-induced type I interferon response at the choroid plexus negatively affects brain function. Science 346:89-93.

Basser PJ, Mattiello J, LeBihan D (1994a) Estimation of the effective selfdiffusion tensor from the NMR spin echo. J Magn Reson B 103:247-254.

Basser PJ, Mattiello J, LeBihan D (1994b) MR diffusion tensor spectroscopy and imaging. Biophys J 66:259-267.

Berl S, Karram K, Scheller A, Jungblut M, Kirchhoff F, Waisman A (2017) Enrichment and isolation of neurons from adult mouse brain for ex vivo analysis. J Neurosci Methods 283:15-22.

Bigler ED, Bazarian JJ (2010) Diffusion tensor imaging: a biomarker for mild traumatic brain injury? Neurology 74:626-627.

Bitko V, Barik S (2008) Nasal delivery of siRNA. Methods Mol Biol 442:7582.

Booth V, Keizer DW, Kamphuis MB, Clark-Lewis I, Sykes BD (2002) The CXCR3 binding chemokine IP-10/CXCL10: structure and receptor interactions. Biochemistry 41:10418-10425.

Broussard JI, Acion L, De Jesús-Cortés H, Yin T, Britt JK, Salas R, CostaMattioli M, Robertson C, Pieper AA, Arciniegas DB, Jorge R (2018) Repeated mild traumatic brain injury produces neuroinflammation, anxiety-like behaviour and impaired spatial memory in mice. Brain Inj 32:113-122.

Cai X, Chiu YH, Chen ZJ (2014) The cGAS-cGAMP-STING pathway of cytosolic DNA sensing and signaling. Mol Cell 54:289-296.

Carlos TM, Clark RS, Franicola-Higgins D, Schiding JK, Kochanek PM (1997) Expression of endothelial adhesion molecules and recruitment of neutrophils after traumatic brain injury in rats. J Leukoc Biol 61:279-285.

Cash E, Zhang Y, Rott O (1993) Microglia present myelin antigens to T cells after phagocytosis of oligodendrocytes. Cell Immunol 147:129-138.

Cheeran MC, Hu S, Sheng WS, Peterson PK, Lokensgard JR (2003) CXCL10 production from cytomegalovirus-stimulated microglia is regulated by both human and viral interleukin-10. J Virol 77:4502-4515.

Chen XH, Siman R, Iwata A, Meaney DF, Trojanowski JQ, Smith DH (2004) Long-term accumulation of amyloid-beta, beta-secretase, presenilin-1, and caspase-3 in damaged axons following brain trauma. Am J Pathol 165:357-371.

Chen Y, Tian H, Yao E, Tian Y, Zhang H, Xu L, Yu Z, Fang Y, Wang W, Du P, Xie M (2017) Soluble epoxide hydrolase inhibition promotes white matter integrity and long-term functional recovery after chronic hypoperfusion in mice. Sci Rep 7:7758.

Chhatbar C, Detje CN, Grabski E, Borst K, Spanier J, Ghita L, Elliott DA, Jordão MJ, Mueller N, Sutton J, Prajeeth CK, Gudi V, Klein MA, Prinz M, Bradke F, Stangel M, Kalinke U (2018) Type I interferon receptor sig- naling of neurons and astrocytes regulates microglia activation during viral encephalitis. Cell Rep 25:118-129.e4.

Cui Y, Zhao D, Sreevatsan S, Liu C, Yang W, Song Z, Yang L, Barrow P, Zhou $X$ (2016) Mycobacterium bovis induces endoplasmic reticulum stress mediated-apoptosis by activating IRF3 in a murine macrophage cell line. Front Cell Infect Microbiol 6:182.

Dai P, Cao H, Merghoub T, Avogadri F, Wang W, Parikh T, Fang CM, Pitha PM, Fitzgerald KA, Rahman MM, McFadden G, Hu X, Houghton AN, Shuman S, Deng L (2011) Myxoma virus induces type I interferon production in murine plasmacytoid dendritic cells via a TLR9/MyD88-, IRF5/IRF7-, and IFNAR-dependent pathway. J Virol 85:10814-10825.

Dash PK, Hylin MJ, Hood KN, Orsi SA, Zhao J, Redell JB, Tsvetkov AS, Moore AN (2015) Inhibition of eukaryotic initiation factor 2 alpha phosphatase reduces tissue damage and improves learning and memory after experimental traumatic brain injury. J Neurotrauma 32:1608-1620.

Deczkowska A, Matcovitch-Natan O, Tsitsou-Kampeli A, Ben-Hamo S, DvirSzternfeld R, Spinrad A, Singer O, David E, Winter DR, Smith LK, Kertser A, Baruch K, Rosenzweig N, Terem A, Prinz M, Villeda S, Citri A, Amit I, Schwartz M (2017) Mef2C restrains microglial inflammatory response and is lost in brain ageing in an IFN-I-dependent manner. Nat Commun 8:717.

Dent KA, Christie KJ, Bye N, Basrai HS, Turbic A, Habgood M, Cate HS, Turnley AM (2015) Oligodendrocyte birth and death following traumatic brain injury in adult mice. PLoS One 10:e0121541.

do Amaral JF, Silva MI, de Aquino Neto MR, Moura BA, de Carvalho AM, Vasconcelos PF, Barbosa Filho JM, Gutierrez SJ, Vasconcelos SM, Macêdo DS, de Sousa FC (2013) Antidepressant-like effect of biseugenol in the mice forced swimming test: evidence for the involvement of the monoaminergic system. Fundam Clin Pharmacol 27:471-482.

Donlin LT, Jayatilleke A, Giannopoulou EG, Kalliolias GD, Ivashkiv LB (2014) Modulation of TNF-induced macrophage polarization by synovial fibroblasts. J Immunol 193:2373-2383.

Einat H, Clenet F, Shaldubina A, Belmaker RH, Bourin M (2001) The antidepressant activity of inositol in the forced swim test involves $5-\mathrm{HT}_{2}$ receptors. Behav Brain Res 118:77-83.

Ejlerskov P, Hultberg JG, Wang J, Carlsson R, Ambjørn M, Kuss M, Liu Y, Porcu G, Kolkova K, Friis Rundsten C, Ruscher K, Pakkenberg B, Goldmann T, Loreth D, Prinz M, Rubinsztein DC, Issazadeh-Navikas S (2015) Lack of neuronal IFN- $\beta$-IFNAR causes lewy body- and Parkinson's Disease-like dementia. Cell 163:324-339.

Farook JM, Shields J, Tawfik A, Markand S, Sen T, Smith SB, Brann D, Dhandapani KM, Sen N (2013) GADD34 induces cell death through inactivation of Akt following traumatic brain injury. Cell Death Dis 4:e754.

Fenwick PS, Macedo P, Kilty IC, Barnes PJ, Donnelly LE (2015) Effect of JAK inhibitors on release of CXCL9, CXCL10 and CXCL11 from human airway epithelial cells. PLoS One 10:e0128757.

Fox GB, Fan L, Levasseur RA, Faden AI (1998) Sustained sensory/motor and cognitive deficits with neuronal apoptosis following controlled cortical impact brain injury in the mouse. J Neurotrauma 15:599-614.

Fu H, Possenti A, Freer R, Nakano Y, Hernandez Villegas NC, Tang M, Cauhy PVM, Lassus BA, Chen S, Fowler SL, Figueroa HY, Huey ED, Johnson GVW, Vendruscolo M, Duff KE (2019) A tau homeostasis signature is linked with the cellular and regional vulnerability of excitatory neurons to tau pathology. Nat Neurosci 22:47-56.

Gentleman SM, Leclercq PD, Moyes L, Graham DI, Smith C, Griffin WS, Nicoll JA (2004) Long-term intracerebral inflammatory response after traumatic brain injury. Forensic Sci Int 146:97-104.

Guida F, Boccella S, Iannotta M, De Gregorio D, Giordano C, Belardo C, Romano R, Palazzo E, Scafuro MA, Serra N, de Novellis V, Rossi F, Maione S, Luongo L (2017) Palmitoylethanolamide reduces neuropsychiatric behaviors by restoring cortical electrophysiological activity in a mouse model of mild traumatic brain injury. Front Pharmacol 8:95.

Harry GJ (2013) Microglia during development and aging. Pharmacol Ther 139:313-326.

Hernandez-Rabaza V, Agusti A, Cabrera-Pastor A, Fustero S, Delgado O, Taoro-Gonzalez L, Montoliu C, Llansola M, Felipo V (2015) Sildenafil reduces neuroinflammation and restores spatial learning in rats with hepatic encephalopathy: underlying mechanisms. J Neuroinflammation 12: 195.

Hilgenberg LG, Smith MA (2007) Preparation of dissociated mouse cortical neuron cultures. J Vis Exp 10:562. 
Hiott DW, Labbate L (2002) Anxiety disorders associated with traumatic brain injuries. Neurorehabilitation 17:345-355.

Holmin S, Mathiesen T (1999) Long-term intracerebral inflammatory response after experimental focal brain injury in rat. Neuroreport 10 : $1889-1891$.

Holmin S, Söderlund J, Biberfeld P, Mathiesen T (1998) Intracerebral inflammation after human brain contusion. Neurosurgery 42:291-298; discussion 298-299.

Holmin S, Mathiesen T, Shetye J, Biberfeld P (1995) Intracerebral inflammatory response to experimental brain contusion. Acta Neurochir 132:110-119.

Hood KN, Zhao J, Redell JB, Hylin MJ, Harris B, Perez A, Moore AN, Dash PK (2018) Endoplasmic reticulum stress contributes to the loss of newborn hippocampal neurons after traumatic brain injury. J Neurosci 38:2372-2384.

Jin X, Yamashita T (2016) Microglia in central nervous system repair after injury. J Biochem 159:491-496.

Johnson VE, Stewart JE, Begbie FD, Trojanowski JQ, Smith DH, Stewart W (2013) Inflammation and white matter degeneration persist for years after a single traumatic brain injury. Brain 136:28 -42.

Jones KJ, Lovett-Racke AE, Walker CL, Sanders VM (2015) CD4 + T cells and neuroprotection: relevance to motoneuron injury and disease. J Neuroimmune Pharmacol 10:587-594.

Jorge RE, Robinson RG, Moser D, Tateno A, Crespo-Facorro B, Arndt S (2004) Major depression following traumatic brain injury. Arch Gen Psychiatry 61:42-50.

Kapoor S, Kim SM, Farook JM, Mir S, Saha R, Sen N (2013) Foxo3a transcriptionally upregulates AQP4 and induces cerebral edema following traumatic brain injury. J Neurosci 33:17398-17403.

Karve IP, Zhang M, Habgood M, Frugier T, Brody KM, Sashindranath M, Ek CJ, Chappaz S, Kile BT, Wright D, Wang H, Johnston L, Daglas M, Ates RC, Medcalf RL, Taylor JM, Crack PJ (2016) Ablation of type-1 IFN signaling in hematopoietic cells confers protection following traumatic brain injury. eNeuro 3:ENEURO.0128-15.2016.

Lampron A, Larochelle A, Laflamme N, Préfontaine P, Plante MM, Sánchez MG, Yong VW, Stys PK, Tremblay MÈ, Rivest S (2015) Inefficient clearance of myelin debris by microglia impairs remyelinating processes. J Exp Med 212:481-495.

Lian H, Roy E, Zheng H (2016) Protocol for primary microglial culture preparation. Bio Protoc 6:e1989.

Liu S, Cai X, Wu J, Cong Q, Chen X, Li T, Du F, Ren J, Wu YT, Grishin NV, Chen ZJ (2015) Phosphorylation of innate immune adaptor proteins MAVS, STING, and TRIF induces IRF3 activation. Science 347:aaa2630.

Liu YP, Zeng L, Tian A, Bomkamp A, Rivera D, Gutman D, Barber GN, Olson JK, Smith JA (2012) Endoplasmic reticulum stress regulates the innate immunity critical transcription factor IRF3. J Immunol 189:4630-4639.

Loane DJ, Byrnes KR (2010) Role of microglia in neurotrauma. Neurotherapeutics 7:366-377.

Loane DJ, Kumar A (2016) Microglia in the TBI brain: the good, the bad, and the dysregulated. Exp Neurol 275:316-327.

Loane DJ, Kumar A, Stoica BA, Cabatbat R, Faden AI (2014) Progressive neurodegeneration after experimental brain trauma: association with chronic microglial activation. J Neuropathol Exp Neurol 73:14-29.

Long JA, Watts LT, Chemello J, Huang S, Shen Q, Duong TQ (2015) Multiparametric and longitudinal MRI characterization of mild traumatic brain injury in rats. J Neurotrauma 32:598-607.

Lopez-Fabuel I, Le Douce J, Logan A, James AM, Bonvento G, Murphy MP, Almeida A, Bolaños JP (2016) Complex I assembly into supercomplexes determines differential mitochondrial ROS production in neurons and astrocytes. Proc Natl Acad Sci U S A 113:13063-13068.

Matveeva V, Khanova M, Sardin E, Antonova L, Barbarash O (2018) Endovascular interventions permit isolation of endothelial colony-forming cells from peripheral blood. Int J Mol Sci 19:E3453.

Maxwell WL, MacKinnon MA, Smith DH, McIntosh TK, Graham DI (2006) Thalamic nuclei after human blunt head injury. J Neuropathol Exp Neurol 65:478-488

McKee CA, Lukens JR (2016) Emerging roles for the immune system in traumatic brain injury. Front Immunol 7:556.

Michlmayr D, McKimmie C (2014) Role of CXCL10 in central nervous system inflammation. Int J Interferon Cytokine Mediat Res 6:1-18.

Mills CD, Ley K (2014) M1 and M2 macrophages: the chicken and the egg of immunity. J Innate Immun 6:716-726.

Moalem G, Leibowitz-Amit R, Yoles E, Mor F, Cohen IR, Schwartz M (1999)
Autoimmune $\mathrm{T}$ cells protect neurons from secondary degeneration after central nervous system axotomy. Nat Med 5:49-55.

Moore SM, Khalaj AJ, Kumar S, Winchester Z, Yoon J, Yoo T, MartinezTorres L, Yasui N, Katzenellenbogen JA, Tiwari-Woodruff SK (2014) Multiple functional therapeutic effects of the estrogen receptor beta agonist indazole-cl in a mouse model of multiple sclerosis. Proc Natl Acad Sci U S A 111:18061-18066.

Nagamoto-Combs K, McNeal DW, Morecraft RJ, Combs CK (2007) Prolonged microgliosis in the rhesus monkey central nervous system after traumatic brain injury. J Neurotrauma 24:1719-1742.

Narayana PA (2017) White matter changes in patients with mild traumatic brain injury: MRI perspective. Concussion 2:CNC35.

Ndode-Ekane XE, Matthiesen L, Bañuelos-Cabrera I, Palminha CAP, Pitkänen A (2018) T-cell infiltration into the perilesional cortex is longlasting and associates with poor somatomotor recovery after experimental traumatic brain injury. Restor Neurol Neurosci 36:485-501.

Nortje J, Menon DK (2004) Traumatic brain injury: physiology, mechanisms, and outcome. Curr Opin Neurol 17:711-718

Olah M, Amor S, Brouwer N, Vinet J, Eggen B, Biber K, Boddeke HW (2012) Identification of a microglia phenotype supportive of remyelination. Glia 60:306-321.

Petrasek J, Iracheta-Vellve A, Csak T, Satishchandran A, Kodys K, Kurt-Jones EA, Fitzgerald KA, Szabo G (2013) STING-IRF3 pathway links endoplasmic reticulum stress with hepatocyte apoptosis in early alcoholic liver disease. Proc Natl Acad Sci U S A 110:16544-16549.

Pino PA, Cardona AE (2011) Isolation of brain and spinal cord mononuclear cells using percoll gradients. J Vis Exp 48:2348.

Pischiutta F, Micotti E, Hay JR, Marongiu I, Sammali E, Tolomeo D, Vegliante G, Stocchetti N, Forloni G, De Simoni MG, Stewart W, Zanier ER (2018) Single severe traumatic brain injury produces progressive pathology with ongoing contralateral white matter damage one year after injury. Exp Neurol 300:167-178.

Porsolt RD, Bertin A, Jalfre M (1977) Behavioral despair in mice: a primary screening test for antidepressants. Arch Int Pharmacodyn Ther 229:327-336.

Qin C, Fan WH, Liu Q, Shang K, Murugan M, Wu LJ, Wang W, Tian DS (2017) Fingolimod protects against ischemic white matter damage by modulating microglia toward M2 polarization via STAT3 pathway. Stroke 48:3336-3346

Qu W, Liu NK, Xie XM, Li R, Xu XM (2016) Automated monitoring of early neurobehavioral changes in mice following traumatic brain injury. Neural Regen Res 11:248-256.

Rodgers KM, Deming YK, Bercum FM, Chumachenko SY, Wieseler JL, Johnson KW, Watkins LR, Barth DS (2014) Reversal of established traumatic brain injury-induced, anxiety-like behavior in rats after delayed, postinjury neuroimmune suppression. J Neurotrauma 31:487-497.

Rodriguez M, Lapierre J, Ojha CR, Kaushik A, Batrakova E, Kashanchi F, Dever SM, Nair M, El-Hage N (2017) Intranasal drug delivery of small interfering RNA targeting Beclin1 encapsulated with polyethylenimine (PEI) in mouse brain to achieve HIV attenuation. Sci Rep 7:1862.

Rojas-Rivera D, Delvaeye T, Roelandt R, Nerinckx W, Augustyns K, Vandenabeele P, Bertrand MJM (2017) When PERK inhibitors turn out to be new potent RIPK1 inhibitors: critical issues on the specificity and use of GSK2606414 and GSK2656157. Cell Death Differ 24:1100-1110.

Rondina C, Videtta W, Petroni G, Lujan S, Schoon P, Mori LB, Matkovich J, Carney N, Chesnut R (2005) Mortality and morbidity from moderate to severe traumatic brain injury in Argentina. J Head Trauma Rehabil 20: 368-376.

Saha P, Gupta R, Sen T, Sen N (2018) Activation of cyclin D1 affects mitochondrial mass following traumatic brain injury. Neurobiol Dis 118:108116.

Schafer DP, Heller CT, Gunner G, Heller M, Gordon C, Hammond T, Wolf Y, Jung S, Stevens B (2016) Microglia contribute to circuit defects in Mecp2-null mice independent of microglia-specific loss of Mecp2 expression. eLife 5:e15224.

Sen T, Sen N (2016) Treatment with an activator of hypoxia-inducible factor 1, DMOG provides neuroprotection after traumatic brain injury. Neuropharmacology 107:79-88.

Sen T, Gupta R, Kaiser H, Sen N (2017) Activation of PERK elicits memory impairment through inactivation of CREB and downregulation of PSD95 after traumatic brain injury. J Neurosci 37:5900-5911.

Sen T, Saha P, Sen N (2018) Nitrosylation of GAPDH augments pathological tau acetylation upon exposure to amyloid-beta. Sci Signal 11:eaao6765. 
Sica A, Mantovani A (2012) Macrophage plasticity and polarization: in vivo veritas. J Clin Invest 122:787-795.

Soares HD, Hicks RR, Smith D, McIntosh TK (1995) Inflammatory leukocytic recruitment and diffuse neuronal degeneration are separate pathological processes resulting from traumatic brain injury. J Neurosci 15:8223-8233.

Stahel PF, Shohami E, Younis FM, Kariya K, Otto VI, Lenzlinger PM, Grosjean MB, Eugster HP, Trentz O, Kossmann T, Morganti-Kossmann MC (2000) Experimental closed head injury: analysis of neurological outcome, blood-brain barrier dysfunction, intracranial neutrophil infiltration, and neuronal cell death in mice deficient in genes for proinflammatory cytokines. J Cereb Blood Flow Metab 20:369-380.

Stirling DP, Yong VW (2008) Dynamics of the inflammatory response after murine spinal cord injury revealed by flow cytometry. J Neurosci Res 86:1944-1958.

The IFN $\beta$ Multiple Sclerosis Study Group (1993) Interferon beta-1b is effective in relapsing-remitting multiple sclerosis: I. Clinical results of a multicenter, randomized, double-blind, placebo-controlled trial. Neurology 43:655-661.

Tan HP, Guo Q, Hua G, Chen JX, Liang JC (2018) Inhibition of endoplasmic reticulum stress alleviates secondary injury after traumatic brain injury. Neural Regen Res 13:827-836.

Tanaka Y, Chen ZJ (2012) STING specifies IRF3 phosphorylation by TBK1 in the cytosolic DNA signaling pathway. Sci Signal 5:ra20.

Taylor JM, Minter MR, Newman AG, Zhang M, Adlard PA, Crack PJ (2014) Type-1 interferon signaling mediates neuro-inflammatory events in models of Alzheimer's disease. Neurobiol Aging 35:1012-1023.

Wakade C, Sukumari-Ramesh S, Laird MD, Dhandapani KM, Vender JR (2010) Delayed reduction in hippocampal postsynaptic density protein-95 expression temporally correlates with cognitive dysfunction following controlled cortical impact in mice. J Neurosurg 113:1195-1201.

Wang G, Zhang J, Hu X, Zhang L, Mao L, Jiang X, Liou AK, Leak RK, Gao Y, Chen J (2013) Microglia/macrophage polarization dynamics in white matter after traumatic brain injury. J Cereb Blood Flow Metab 33:1864-1874.

Wang J, Ma MW, Dhandapani KM, Brann DW (2017) Regulatory role of NADPH oxidase 2 in the polarization dynamics and neurotoxicity of microglia/macrophages after traumatic brain injury. Free Radic Biol Med 113:119-131.

Wang N, Liang H, Zen K (2014) Molecular mechanisms that influence the macrophage $\mathrm{m} 1-\mathrm{m} 2$ polarization balance. Front Immunol 5:614

Wilson S, Raghupathi R, Saatman KE, MacKinnon MA, McIntosh TK, Graham DI (2004) Continued in situ DNA fragmentation of microglia/ macrophages in white matter weeks and months after traumatic brain injury. J Neurotrauma 21:239-250.

Xia Y, Pu H, Leak RK, Shi Y, Mu H, Hu X, Lu Z, Foley LM, Hitchens TK, Dixon CE, Bennett MVL, Chen J (2018) Tissue plasminogen activator promotes white matter integrity and functional recovery in a murine model of traumatic brain injury. Proc Natl Acad Sci U S A 115:E9230-E9238.

Xiong X, Barreto GE, Xu L, Ouyang YB, Xie X, Giffard RG (2011) Increased brain injury and worsened neurological outcome in interleukin-4 knockout mice after transient focal cerebral ischemia. Stroke 42:2026-2032.

Xu Z, Cho H, Hartsock MJ, Mitchell KL, Gong J, Wu L, Wei Y, Wang S, Thimmulappa RK, Sporn MB, Biswal S, Welsbie DS, Duh EJ (2015) Neuroprotective role of Nrf2 for retinal ganglion cells in ischemiareperfusion. J Neurochem 133:233-241.

Yin Y, Li E, Sun G, Yan HQ, Foley LM, Andrzejczuk LA, Attarwala IY, Hitchens TK, Kiselyov K, Dixon CE, Sun D (2018) Effects of DHA on hippocampal autophagy and lysosome function after traumatic brain injury. Mol Neurobiol 55:2454-2470.

Yu F, Sharma S, Edwards J, Feigenbaum L, Zhu J (2015) Dynamic expression of transcription factors T-bet and GATA-3 by regulatory T cells maintains immunotolerance. Nat Immunol 16:197-206.

Zhao X, Wang H, Sun G, Zhang J, Edwards NJ, Aronowski J (2015) Neuronal interleukin-4 as a modulator of microglial pathways and ischemic brain damage. J Neurosci 35:11281-11291.

Zhu C, Xu Q, Wang C, Mao Z, Lin N (2017) Evidence that CA3 is underling the comorbidity between pain and depression and the co-curation by Wu-Tou decoction in neuropathic pain. Sci Rep 7:11935.

Ziebell JM, Morganti-Kossmann MC (2010) Involvement of pro- and antiinflammatory cytokines and chemokines in the pathophysiology of traumatic brain injury. Neurotherapeutics 7:22-30. 